\title{
Sage und Geschichte in den Patriarchenerzählungen.
}

Von Professor Dr. Hugo Greßmann in Berlin.

ED. MEYeR hat in seinem Buche über ,die Israeliten und ihre Nachbarstämme" (Halle 1906) aufs neue die Frage nach dem Wesen und Ursprung der Patriarchengestalten aufgeworfen und, unter Ablehnung der stammesgeschichtlichen Deutung, ihre Herkunft aus der Mythologie verfochten. Eine Auseinandersetzung mit dieser gut begründeten Anschauung verspricht nur dann lohnenden Ertrag, wenn sie sich nicht auf die Personen allein beschränkt, sondern zugleich zu einer Untersuchung über die Genesis der Erzählungen erweitert. Im Anschluß an die von GUNKEL gewonnenen Resultate der Sagenanalyse, die überall als bekannt vorausgesetzt werden, und angeregt zu einer Nachprüfung der von WUNDT in seiner "Völkerpsychologie“ aufgestellten Theorien über die Entwicklung der allgemeinen Literaturgeschichte, will die folgende Abhandlung versuchen, Bausteine zu einem neuen Aufri@ der israelitischen Sagengeschichte $z u$ liefern.

I a. Der Name Abrâm ist bisher nicht sicher erklärt worden. $\mathrm{Da}$ aber nebeneinander stehen

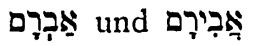

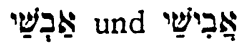

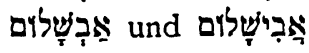

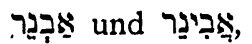

so muß Abrâm eine Kurzform von Abîrâm sein x. Nun fragt sich, ob "ב̣ is in diesen Kompositionen als "mein Vater" oder als "Vater" im stat. c. aufzufasșen ist. Zugunsten der ersten Möglichkeit könnte man einen Namen wie Vater ist Jahu'. 'Trotzdem wird man sich aus mehreren Gründen für die zweite Möglichkeit entscheiden müssen. Denn zunächst wäre die Kurzform

2 So mit Recht auch ED. Meyrr, Israeliten. S. 265. Über die folgende Frage zußert er sich nicht. Da er übersetzt "holer Vater". oder „der Vater ist erhaben“, so scheint er den ersten Bestandteil nicht als Suffixform zu betrachten.

Zeitschrift E. d. alttest. Wiss. Jahrg. 30. 1910. 
bei cinem Suffix der ersten Pcrson sehr auffällig, während beide Formen im stat. c. auch sonst bezeugt sind. Es kommt ferner hinzu, daf in ana-

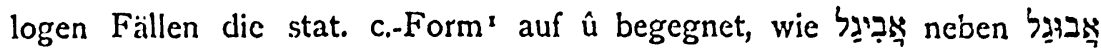

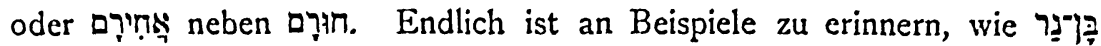

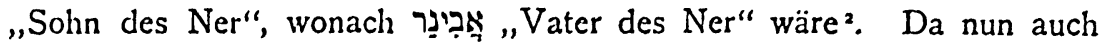
ㄱ als Nomen proprium nachweisbar ist, so wäre scheinlichsten Etymologie als „Vater des Ram" zu deuten; dement-

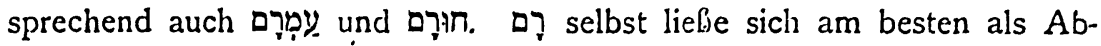

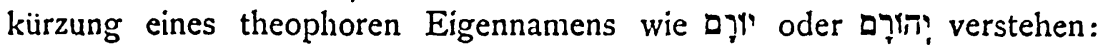
"Jahu ist erhaben". Man darf indessen zweifeln, ob diese Ableitung richtig ist. Denn die meisten der mit אב zusammengesetzten

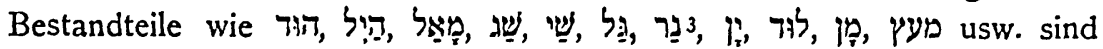
für uns völlig undurchsichtig. Die Möglichkeit fremden Ursprungs muß daher auch für

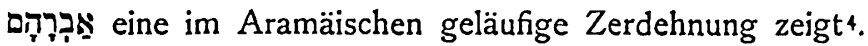

Nun hat UNGNAD neuerdings durch die Veröffentlichung des babylonischen Namens Ab(am)-râma aus der Zeit der „Hammurapidynastie" einen interessanten Beitrag geliefert's, der geeignet scheint, neues Licht auf den Namen des Patriarchen zu werfen. Dazu schreibt mir Herr Dr. RaNkE: „In Kontrakttafeln aus der babylonischen Stadt Dilbat begegnet mehrfach der Personenname A-ba-am-ra-ma ${ }^{6}$ (Varianten: A-ba-ra-ma und A-ba-am-ra-am), der bisher noch nicht belegt war, der sich aber ohne weiteres einer bekannten Gruppe von babylonischen Namen nicht religiösen Inhalts einfügt, welche von dem Verhältnis des neugebornen Kindes zur Familie handeln. Solche Namen sind z. B.7:

I. Von einer alten "Kasusendung“, wie KaUTzSCH S 90 und andere Grammatiker behaupten, kann wohl keine Rede sein.

2 Man muß sich vor dem Irrtum hüten, als ob der "Vater des Ner" wirklich einen Sohn namens Ner gehabt habe. Diese bei den modernen Arabern übliche Benennung des Vaters ist im Alterlum nicht nachweisbar. Die Namen sind vielmehr gegeben und werden, genau so wie bei uns, ohne Rücksicht auf den Sinn verliehen.

3 אביגל übersetzt man gewöhnlich „mein Vater ist Jubel“; vgl. Nowack zu I Sam 25 3. Aber ל kann nicht gut "Jubel" heißen. Und אבינר ,mein Vater ist eine Lampe"?

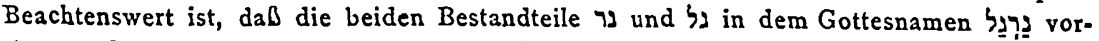
liegen, den man freilich bisher auch nicht erklären kann, der aber sicher nicht hebräisch ist.

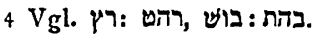

5 A. Ungnap, Untersuchungen zu den ... Urkunden aus Dilbat (Beiträge zur Assyr. VI, 5). 1909. S. 60.

6 UNGNAD a. 2. O. S. 82.

7 Wo nichts Anderes angegeben, finden sich die Belege bei H. RANKE, Early Babylonian Personal Names. Philadelphia 1905. 
Abam-là-îdi x "Er hat den Vater nicht kennen gelernt". A ham-arSi „Is habe einen Bruder bekommen“. A ham-nerši ${ }^{2}$ "Wir haben einen Bruder bekommen". Aham-iršu "Sie haben einen Bruder bekommen". Aham-utta ${ }^{3}$ "Ich habe einen Bruder gefunden". Aham-nutta "Wir haben einen Bruder gefunden". Aḩhu-waqrû ${ }^{5}$ „Die Brüder sind teuer".

Ahuni ${ }^{6}$, (Er ist) unser Bruder".

Ahušina „(Er ist) ihr (der älteren Schwester) Bruder".

Im Anschluß an diese Namen wird man Abam-râma am besten „Er hat den Vater lieb" übersetzen 7; ein Lächeln, das die glückliche Mutter auf den Zügen des Neugebornen zu sehen glaubte, als er seinem Vater gezeigt wurde, mag einem solchen Namen den Ursprung gegeben haben. Auf jeden Fall haben wir es hier mit einem echt babylonischen Namen - nicht etwa mit einem der zu jener Zeit in Babylonien nicht ganz seltenen "westsemitischen" Namen - zu tun; dafür ist die Akkusativform abam beweisend. Freilich ist diese Schreibung abam nur eine historische, und es läßt sich mit Sicherheit behaupten, daß der Name nicht viel anders als $\mathrm{Ab}$-râm ausgesprochen wurde ${ }^{8}$. Ist aber die Zusammenstellung dieses $\mathrm{Ab}$-ràm mit dem Namen des Patriarchen Abrâm berechtigt, so ist der Schluß unabweislich, daß in letzterem nicht ein hebräischer, sondern ein babylonischer Personenname zu erkennen ist". - Dieser Name, so darf man den Ausführungen RANkEs hinzufügen, ist dann indessen bei den hebräischen Stämmen, wie Abîrâm und analoge Formen lehren, häufig verwandt. und kaum noch als ausländisch empfunden worden. Aber sieht man von der Etymologie und der Herkunft des Namens, die immer bis zu einem gewissen 'Grade problematisch bleiben werden, einmal ganz ab, so steht doch die Tatsache unumstößlich fest, daß Abrâm im Hebräischen wie im Babylonischen ein geläufiger Personenname gewesen ist. Dadurch

I Ungnad a. x. O. S. 82: „d. i. Postumus".

2 So sind auch die Personal Names S. 62 unter Aham-kallim gebuchten Stellen zu lesen.

3 UNGNAd a. 2. O. S. 83. Möglich ist auch die Übersetzung „Er hat einen Bruder gefunden" (so UNGNAD).

4 Variante Ah-nutta; vgl. MeISSNER, Altbabylonisches Privatrecht Nr. 92: 2 und 2 a.

5 UNGNAD a. a. O. S. -83.

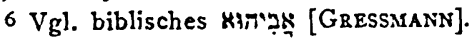

7 Auch UNGNAD übersetzt: "Den Vater hat er liebgewonnen(?)", doch ist zu betonen, daS diese Übersetzung nicht absolut sicher.ist.

8 Vgl. die Variante Abam-râm, ferner Ah̆-nutta neben Aham-nutta. 
allein schon wird seine Deutung als cin ursprünglicher Gottesname unmöglich.

In ägyptischen Urkunden ist der Name Abrâm nur einmal belegt. Die Schoschenkliste erwahnnt einen palästinischen Ort, vielleicht bei $\mathrm{He}$ bron, namens P3 ḷkr? 3brm", den SPIEGELBERG ${ }^{2}$ „Feld des Abrâm“ übersetzt ${ }^{3}$. Diese mit Rehabeam gleichzeitige Notiz ist deshalb von Interesse, weil sie ebenfalls von einem Gotte Abram nichts weil

Aber auch das in der Genesis Erzählte spricht nicht für einen anfangs mythischen Charakter Abrahams. Das Einzige 4, was man zur Rechtfertigung dieser Behauptung herangezogen hat, ist die Nachricht von der Wohnung Abrahams unter dem Baum 5 Mamre bei ${ }^{6}$ Hebron, dessen Heiligkeit aus dem dort gebauten Altare erhellt (Gen 13 18). Diese Tradition kann in der Tat stutzig machen und die Frage nahelegen, ob nicht Abraham eine Baumgottheit Hebrons ${ }^{7}$ war. Aber es bleibt die große Schwierigkeit, daß der Baum des Gottes Abraham nicht Abraham, sondern Mamre heibt. Woher dieser Name kommt, weil ED. MEYer nicht $z \mathrm{u}$ erklären. Ist es nicht wahrscheinlicher $\mathrm{zu}$ vermuten, da@ der Baum ursprünglich dem (hettitischen?) Gotte Mamre heilig war, dann aber durch die israelitische Tradition entheiligt wurde? Solche Profanation pflegt ja gewöhnlich in der Form der Polemik zu geschehen: „Bewahre! Der Baum Mamre ist nicht deshalb ein Gottesbaum, weil hier ein Altar des Gottes Mamre steht, sondern deshalb, weil hier Abraham wohnte,

I W. MAX MÜlLER, Egyptol. Researches. Tafel 81 Nr. 7172.

2 Spiegelberg, Ägyptische Randglossen zum Alten Testament. S. $13 \mathrm{f}$.

3 RaNke schreibt mir dazu: „Die Liste selbst bietet freilich zwei Namen: p3 lakr und 3 brm. Ob SpIegelbergs Zusammenziehung dieser beiden Namen zu einem einzigen berechtigt ist, stehe dahin; doch kommen derartige Zertrennungen von zusammengehörigen Namen durch den unkundigen Steinmetzen allerdings vor".

4 Die Vermutungen Ed. Meyers, Israeliten S. 263 f. über die vier Götter von $\mathrm{He}$ bron hat GunKEL ${ }^{3} \mathrm{~S} 200$ treffend zurückgewiesen. Gen 18 ist ein nicht bodenständiges Märchen (s. u.), das erst relativ spät in Hebron lokalisiert worden ist. Die Verehrung der (drei, warum vier?) Engel durch die späteren "Heiden" geht auf Gen 18 zurüch. Vielleicht ließe sich die These ED. Mexers so modifizieren, daß der Name Hebrons „Vierstadt" mit Enak (aber nicht Abraham!) und seinen drei Söhnen Ahiman, Scheschai und Talmai, den vier Geschlechtern (warum Göttern?) der Stadt, zusammenhängt. Übrigens bringt Hieronymus (vgl. Eusebius, Onomasticon ed. Klostermann S. 7 irff.) den Namen Vierstadt mit vier dort begrabenen Männern zusammen: Abrabam, Isaak, Jakob, Adam magnus.

5 So wohl richtiger als der Plural.

6 Der Baum stand nicht in der Stadt. Abraham bleibt naturgemäß vor den Toren der Stadt.

7 Damit wäre Abraham noch lange nicht eine „kalibbitische Gottheit“, wie

ED. MEyer will. 
der den Altar erst zu Ehren Jahwes errichtet hat". Auf diese Weise konnte sich Israel dẹn fremden Kultort wohl aneignen.

Sara und Saraj sind ebenfalls zwei dialektisch verschiedene Formen. Saraj, wie 'ִ̣ gebildet, entspricht der arabischen Femininendung aj = hebr. $\pi$. LAGARDE hat zuerst auf den nabatäischen Gott דושרא =

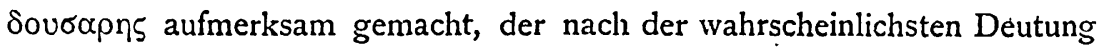
so heißt als „Herr (der Landschaft) von eš-šarā“, wie Gebalene noch heute im Munde der Araber genannt wird (Dalman Petra S. 49). Auch die analoge Namensform des arabischen Gottes Dhu 1Chalasa scheint auf die Verbindung mit einem Ortsnamen hinzuweisen (WeLlHAUSEN Reste ${ }^{x}$ S. $42 \mathrm{ff}$ ). Für die Erklärung "Herr der (Göttin) Sara" spricht nichts, auch nicht die Inschrift aus Bosra im Hauran'. Aber das ist in der Tat durchaus wahrscheinlich, daß Saraj den Namen einer Landschaft trägt wie Eglon, Balak, Sihon, Ebal u. a. Gerade der Ortsname eš-šarā ist weit verbreitet ${ }^{2}$, so da@ wir kein Recht haben, an eine bestimmte Gegend, etwa die von Petra, zu denken.

Nun hat man freilich auch Sara für eine zur Heroine herabgesunkene Gottheit und zwar direkt für die Göttin der Machpela ausgegeben. Man wird das Gewicht des Grundes zugestehen müssen, selbst wenn man ihn nicht für zwingend hält. Die heute noch heilige Höhle von Hebron wird seit uralten Zeiten denselben Charakter bewahrt haben. Da Sara besonders auch mit ihr verbunden ist, so liegt es durchaus nahe, sie als ihre Göttin zu betrachten. Aber' es bleibt, wie beim Baume Mamre, die Schwierigkeit des Namens, die von ED. MEYER, dem Hauptverfechter dieser These, nicht beseitigt wird. Machpela ist, wie es scheint, der Name der Gegend, in der sich die Höhle befindet. Ist aber Saraj, wie oben gezeigt, wirklich ein Ortsname, so ist der Zusammenhang mit der Machpela nicht ursprünglich und damit die ganze mythische Konstruktion hinfällig. Wäre indessen Machpela der Name der Höhle selbst, so würde Machpela am ehesten das nomen proprium der dort verehrten Göttin sein. Jedenfalls begreift man nicht, warum die angeblich der Sara geweihte Höhle noch einen anderen, völlig unerklärlichen Namen besitzt. Auch hier wird vermutlich der Hergang bei Übernahme der fremden Kulthöhle durch die Israeliten ähnlich gewesen sein wie beim Baume Mamre, indem man die eigene Heroine an die Stelle der fremden Gottheit setzte

I Vgl. gegen ED, MEYER, Israeliten S. 269f. die treffenden Bemerkungen von Eerdmans, Alttestamentliche Studicn II. Gießen 1.908. S. 13.

2 Wellhausen, Restex S. 47; NöldekE, ZDMG 41 S. 711. 
und zugleich den heiligen Charakter des Ortes leugnete, oder ihm wenigstens einen anderen Sinn gab: Hier wohnt nicht diese oder jene Gottheit, sondern hier ist Sara, unsere Stammesmutter, begraben. Da die Hebräer die Höhle als anfängliche Grabstätte Saras, nicht als die Abrahams, betrachteten, so wird man behaupten dürfen, daß das ursprüngliche Kultheiligtum einer weiblichen Gottheit gehörte.

b) Die Namen Ismael, Isaak, Jakob und Joseph sind in der gleichen Weise gebildet. Es sind theophore Namen, teils volle (Ismael), teils verkürzte (Isaak, Jakob, Joseph), aus dem Worte êl "Gott" und einer Imperfektform bestehend, die eine Aussage über diesen $\mathrm{El}$ enthält. „Derartige Bildungen“, so schreibt mir Dr. RANKE, „finden sich häufig unter den südarabischen Namen " sowie unter den "westsemitischen“ Namen der Hammurapizeit, deren Bedeutung uns keineswegs immer verständlich ist. Vgl. zB. ${ }^{2}$ Jabnik-êl, Jadah-êl (Gott weiß), Jadih-êl, Jahzzar-êl (Gott hilft), Jamlik-êl (Gott ist König?), Jamruṣ-êl 3, Japa-êl, Japi-êl, Jarbiêl (Gott mehrt), Jaškur-êl4, Jasi'el4, Jauhi-êl 5 , ferner die danęben vorkommenden Kurznamen Jadihum (vgl. Jadih-êl), Jaḩdunum4, Jaḩzirum (vgl. Jahzar-êl), Jakbarum 4, Jakûnum s, Japqudum 4, Japium (vgl. Japi-êl), Jarhamu, Jašarum, Jaširum, Jašubum, Jatarum. Wie man aus den zuletzt aufgezählten Kurznamen auf Vollnamen mit -êl als zweitem Element schließen muß, wird man dies auch bei Jakob, Isaak und Joseph ${ }^{6}$ tun dürfen. Mit dem vorauszusetzenden hebräischen Vollnamen Ja'qôb-êl stimmt völlig überein der bisher zweimal belegte Jahqub-êl7; damit identisch ist wahrscheinlich die viermal begegnende Form Jaqub.êl und die Kurzform Jaqubum ${ }^{8}$. Bemerkenswert ist, dab auch der Name Ismael in den altbabylonischen Kontrakten als Personenname unter der Form Jas. mah-el (Gott hört) erscheint. Unter allen diesen ,,westsemitischen" Namen S. $82 \mathrm{f}$.

I Vgl. HoMmel, Die altisraelitische Überlieferung in inschriftlicher Beleuchtung

2 Wo nichts Anderes angegeben, finden sich die Belege bei H. RANkE, Personal Names. 3 UNGNAD a. a. O.

4 H. Ranke, Early Babylonian Legal and Business Documents. Philadelphia 1906.

5 UNGNAD a. a. O.

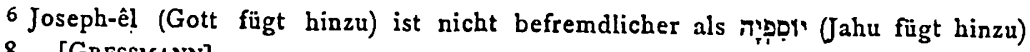
Esta 8 10 [GressmanN].

7 So ist, worauf mich UNGNAD aufmerksam gemacht hat, sicher zu lesen anstatt Jahbbar-êl (Personal Names S. II3). Theoretisch möglich wäre freilich auch Jaḩkub-êl, Jah-qup-el, Jahkkup-êl.

8. Ursemitisches 'Ajin wird in Keilschrift bald durch h wiedergegeben, bald nicht ausgedrūckt. Anstatt Jaqub-êl und Jaqubuin sind auch die Lesungen Jaqup-, Jakub- und Jakup-êl, sowie Jaqupum, Jakubum und Jakupum möglich. 
der Hammurapizeit ist kein einziger, in dem die Imperfektform einen Gottesnamen bezeichnet, wie ausdrücklich hervorgehoben sei, da ED. MEYER neuerdings den Namen Ismael „'Er hört' ist El" übersetzen und auch die Namen Jakob und Isaak als alte Gottesnamen auffassen will. Zum Beweis für einen Gottesnamen Jakob wird der auf zahlreichen Skarabäen gefundene Name eines Hyksoskönigs herangezogen. $\mathrm{Er}$ wird J'pq-hr (so meistens), J'qp-hr, J'qb-hr und Jqb-hr ${ }^{2}$ geschrieben und mit "Ja'qôb ist zufrieden" übersetzt. Nun ist aber an diesem Namen fast alles unsicher. Wenn die Übersetzung des zweiten Elementes richtig wäre ${ }^{3}$, so müßste in dem ersten Teil des Namens freilich ein Gottesname gesucht werden, dessen Lesung aber keineswegs feststeht; neben J'qb wären J'pq und J'qp (Jqb scheint defektive Schreibung) durchaus in gleicher Weise möglich. Ist aber die Übersetzung von hr unrichtig und es ist durch nichts ausgeschlossen, dab hier ebenfalls ein nichtägyptisches Wort vorliegt - so tappt man wieder völlig im Dunkeln. Der Name des Hyksoskönigs allein kann jedenfalls für die Erklärung Jakobs als Gottesname nicht ausschlaggebend sein. Ebenso wenig die unanfechtbare Lesung J'qb-3r(l) = Ja'qôb-êl als Ortsname in der Liste der von Thutmosis III. eroberten palästinischen Städte" "4. - Wie der Personenname Ismael zum Stammesnamen geworden ist, so gut konnte auch der Personenname Jakobel zum Ortsnamen werden; es liegen eine Reihe von Parallelen vor: Jabneel, Jephthahel, Joktheel, Jesreel usw.

Während der Name Jakob resp. Jakobel nicht sicher zu deuten ist ${ }^{5}$,

× Geschichte des Altertums² I, 2. S. 371. Ebenso schon in den: Israeliten S. 252: [Diese seltsame Hypothese ED. MEYERs, die eine unheimliche Fülle verschollener Gottesnamen und eine eigentümliche Namenbildung voraussetzt, wird schwerlich auf Anerkennung rechnen düríen. Vgl, auch die Ausführungen bei EERdNaNs Alttest. Studien II. S. 9 fi. GRESSManN].

2 M. PIEPER, Die Könige Ägyptens zwischen dem mittleren und neuen Reiche. S. 36 Nr. 10. Ferner George Fraser, Scarabs Nr. 181. Newberry, Scarabs Taf. XXII Nr. 27. Petrie, Historical Scarabs Nr. 35I. Petrie, Diospolis parva Taf. XXVII.

3 Dafür wird der Name 'nt-hrtj angeführt ;,die (semitische) Göttin Anat ist zufrieden", den ein Pferd Sethos I. trägt. Der Name eines anderen Hyksoskönigs 'nt-hr, der vielleicht auch die Göttin Anat enthält, kann die Frage nach keiner Seite hin entscheiden. Bisher ist überbaupt kein Hyksosname als sicher semitisch erwiesen. ED. MEYER hält neuerdings selbst die Hyksos nicht für Semiten, sondern für Hettiter.

4 W. MAX MÜLLER, Die Palästinaliste Thutmosis III (Mitteilungen der Vorderasiatischen Ges. 1907,1$)$ S. 27 Nr. 102 und Taf. III. - Über den Ortsnamen Išp.êl vgl. ebd. S. $23 \mathrm{Nr} .78$ und Spiegerberg, Randglossen S. 13. Die Gleichung mit Joseph-êl ist sehr fraglich, da die Konsonanten nicht übereinstimmen.

5 Die vom Text selbst angedeutete Übersetzung "El ist listig“ paßt nicht recht, da man schwerlich eine solche Eigenschaft dem El beilegen wird. Eher "El belohnt"? 
ist der Name Isaak resp. Isaakel völlig durchsichtig: "Gott lacht". Bei ihm soll nach ED. MEYER u. a. der mythische Ursprung der Gestalt am klarsten sein. Der "Schrecken Isaaks", bei dem Jakob schwört (3I 4253 ), soll der Kultusname des Gottes von Beerseba sein. Isaak stehe cuphemistisch für den "grimmen Blick". Dazu stimme die Forderung des Menschenopfers, die der Sage Iphigeniens völlig parallel sei: „Wie hier aus dem Beinamen der Artemis Iphigeneia sich die Heroine entwickelt hat, die ihr geopfert wird, .... so zweigt sich von dem Gotte ,der Schrecken Isaaks' der zum Opfer bestimmte Knabe Isaak ab" ‘. Merkwürdig ist zunächst das Schwanken des Gottesnamens, der bald „Isaak“, bald "Schrecken Isaaks" sein soll. Wo existiert ferner eine analoge Form des Gottesnamens פחד "der Schrecken (ist) ,Er lacht"“? Außerdem müßte nach den angeblichen Parallelen wie Ismael, Israel, Jerachmeel der Name lauten: צחק פחד. Endlich ist uns der Name des Gottes von Beerseba überliefert, aber nicht als Isaak oder Schrecken Isaaks, sondern als עולים 21 33. Allerdings behauptet ED. MEYER, dieser Name sei völlig indifferent und solle nur das graue Altertum des Kultus bezeugen; denn sonst müsse man dem Schriftsteller auch glauben, daß der Kultus "nur" in Anrufungen und Räuchern bestanden habe, daß „aber nicht geopfert worden sei"“2. Aber warum soll denn das Räucheropfer, das für die Bamoth durchaus charakteristisch ist, kein Opfer sein? 3 Warum soll êl 'ôlâm als Name des dôd von Beerseba eine künstliche Schöpfung sein, ist doch die Betonung der Ewigkeit bei den ägyptischen Göttern ein fast ständiges Prädikat? Die vielen Schwierigkeiten, die sich der mythologischen Hypothese entgegenstellen, sind der beste Beweis, daß die Konstruktion falsch ist. מחר יצחק ist nicht anders zu beurteilen wie הביר יעקב. So wenig wie Jakob kann Isaak Gottesname sein. Aller Wahrscheinlich-

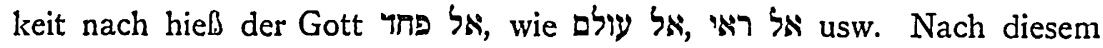
führt Isaak, der eigentlich "Gott ist schrecklich" genannt sein sollte, den euphemistischen Namen "Gott lächelt". Man hat aber durchaus keine Ursache, den Wohnsitz dieses Numens nach Beerseba zu verlegen. Die Opferung Isaaks, die wohl mit jenem furchtbaren El zusammenhängt, hat sicher nicht in Beerseba, sondern, wie GunkEL wohl richtig erkannt hat, in Jeruel stattgefunden. So ist auch dieser Grund hinfällig, der uns angeblich am meisten zwingen soll, Isaak und damit auch die anderen Patriarchengestalten für ursprüngliche Götter $z u$ halten 4 .

I Ed. MeYer, Israeliten S. 255.

2 Ebd. S. 258.

3 Das Räucheropfer ist

in Israel uralt, wie sich durch eine Fülle von Beweisen dartun ließe.

4 Über die Jakob. und Josepherzählungen s, u. in anderem Zusammenhange: 
2. Die Namen der Patriarchen Abraham, Isaak, Jakob und Joseph sind demnach weder als Götter- noch als Stammesnamen nachweisbar, sind auch nicht als solche wahrscheinlich gemacht, wohl aber als simple Personennamen wie Hinz und Kunz. Es gilt nun, daraus die Konsequenzen zu ziehen und die Frage $\mathrm{zu}$ beantworten, wie diese Tatsache mit den überlieferten Erzählungen vereinbar ist. Alle Theorien, die, von den angeblichen Götter- resp. Stammesnamen ausgehend, die Geschichten der Erzväter prinzipiell als ursprüngliche Götter- resp. Stammesgeschichten deuten, sind als unhaltbar abzulehnen; wenn auch faktisch vereinzelte Mythen- und Stammesmotive vorhanden sein mögen, so sind doch die Eigennamen von hier aus nicht zu erklären. Wie denn nun? Dürfen wir etwa folgern, daß jetzt die traditionelle Auffassung von den Patriarchen als historischen Einzelpersonen gerechtfertigt sei und da $₫$ man ihre Erlebnisse als historische Ereignisse zu betrachten habe? Dieser voreilige Schlub, der einer apologetischen Anschauung nahe liegen mag, würde vor der Kritik nicht bestehen können, da er dem stark sagenhaften Charakter der Genesis keine Rechnung trägt und da er Ungeschichtliches nicht plötzlich in Geschichtliches zu verwandeln vermag. Obgleich Hans und Gretel wirklich Personennamen sind, wie niemand bezweifeln wird, bleibt dennoch das nach ihnen benannte Märchen ein Märchen und kann durch keine Kunst der Apologetik als eine Geschichtserzählung hingestellt werden. Um einen Ausweg aus diesem Dilemma zu finden, muß der Grundstock der Patriarchenerzählungen etwas genauer untersucht werden.

a) Analysiert man die von Abraham handelnden Geschichten in dem Werk des Jahwisten und Elohisten, wie es von GUNKEL geschehen ist, so trifft man als die älteste Komposition, in die alles Übrige hineingearbeitet ist, den Sagenkranz von Abraham und Lot'. Er ist aus folgenden Einzelsagen zusammengeflochten: I. aus der Abstammungssage, die Abraham mit Haran verbindet; 2. aus den Kultusortssagen, welche die Altäre bei Sichem und Bethel auf Abraham zurückführen; 3. aus den Stammessagen, die Lot als Vater Ammons und Moabs kennen und von seiner Verwandschaft mit Abraham und dessen Nachkommen wissen; 4. aus den beiden Sagen von Abraham zu Hebron und von Lot zu Sodom. Die ursprünglich selbständigen Sagen sind von den Erzählern miteinander verbunden, indem sie Abraham von Ort $\mathrm{zu}$ Ort wandern lassen. Die „Wanderüng" oder, wie man auch zu sagen pflegt, das „No-

I Gen 12 I-8 18 i-16. 19 I-28 19 30-38. Vgl. das Nähere bei GunkEL ${ }^{3}$ S. 159 ff. 
madentum" dieses Patriarchen beruht hicr also nicht auf irgend welcher geschichtlichen Erinnerung, sondern ist eine künstliche Konstruktion der Sagensammler, um verschiedene Traditionen zu einer Einheit zusammenzuschweißen. Diese elcmentare Erkenntnis der Sagenforschung macht alle modernen Bestrebungen, die „Wanderung Abrahams aus Ur in Chaldää nach Hebron" mit Hilfe der Phantasie als lebendige Wirklichkeit zu gestalten, von vornherein als aussichtslos zu nichte. Kaum irgendwo sind die Resultate der Sagenforschung so bequem nachzuprüfen wie gerade hier, wo die Einzelsagen noch ziemlich lose auseinander fallen. Denn glücklicher Weise haben die israelitischen Erzähler kein Interesse daran gehabt, den Zug Abrahams weiter auszumalen, was an sich leicht möglich gewesen wäre. Es fehlt jede konkrete Schilderung historischer oder kultureller Art. Die vier Stationen sind einfach aneinander gereiht, als wären es vier Tagereisen von Haran bis nach Hebron und als wäre Palästina im Übrigen eine tabula rasa. Man hört von keinem Zusammenstoß des Erzvaters mit der ansässigen Bevölkerung des Landes, die wohl eine Handelskarawane, aber keinen Volksstamm friedlich ${ }^{x}$ das Kulturgebiet hätte durchziehen lassen, mochte es sich um Nomaden, Halbnomaden oder Ackerbauer handeln. Mit derselben Geschwindigkeit wie Abraham kommt Sinuhe in umgekehrter Richtung durch Palästina, von Ägypten und der Sinaihalbinsel nach Byblos und Kedem, indem ihn ein Land dem anderen weitergibt ${ }^{2}$. Es wäre falsch, wenn man aus dem Mangel an Reiseerlebnissen und Abenteuern in Palästina schlieben wollte, daß dort damals noch keine Städte oder nennenswerten Ortschaften existiert hätten ${ }^{3}$. Vielmehr liegt eine primitive Art der Darstellung vor: die Technik der Reisebeschreibung ist noch nicht ausgebildet. Ansätze dazu finden sich im Buche Exodus, wo wenigstens die "Wüstenstationen“ aufgezeichnet sind, die den Weg angeben. Einen dürftigen Anfang mag man auch hier in der Genesis konstatieren, wenn Abraham und Lot von Bethel aus wie moderne Reisende das südliche Palästina überschauen, den

I Charakteristisch für die Unklarheit, die A. Jerenias kennzeichnet, ist die Vorstellung von einem "Eroberungszug" Abrahams, "wenn auch in der mildesten Form" ( $\mathrm{ATAO}_{2} \mathrm{~S}$. 328). Wie ist denn ein solcher Zug zu denken? Da die biblische Erzählung überhaupt nichts von ihm weiß, so redet Jeremins von einer „Idealisierung des Be. richtes". Also ein idealer Eroberungszug?

2 Vgl. Gressmann, Texte und Bilder. Bd. I, S. 21 If.

3 So hat Girdiner geschlossen: Eine neue Handschrift des Sinuhegedichtes (Sitzungsbericht der Berliner Akademie 1907 S. $142 \mathrm{ff}$.). Dagegen spricht schon das Netz von Festungen und Städten, mit denen Palästina zur Zeit Thutmosis' III. und der Amarna. briefe überzogen ist. 
abweichenden Charakter der Landschaften erkennen und dann in die verschiedenen Sitze ziehen. Denn dort trennen sich die Straßen: die eine führt über Jericho zur Jordanebene hinab ${ }^{x}$ in die Gegend des Toten Meeres, wo sich Lot niederläbt, die andere bleibt auf dem Kamm des Mittelgebirges und bringt den Wandernden direkt südwärts bis vor die Tore Hebrons. Die Idee von dem gemeinsamen Zuge Abrahams und Lots und alles, was damit zusammenhängt, ist verhältnismä円ig jungen Ursprungs, weil sie die Überzeugung von der Verwandtschaft beider zur Voraussetzung hat. Darauf aber ist man erst verfallen, als Lot zum Stammvater der historischen Völker Moab und Ammon geworden war und ihre ethnologische Zusammengehörigkeit mit Israel feststand. Auch das, was von Abraham in Sichem und Bethel berichtet wird, hat nur die Form einer kurzen Notiz, während uns in der Jakobtradition ${ }^{2}$ bessere, anschaulichere und farbenfrohere Erzählungen begegnen, so daß Abraham mit jenen Orten ursprünglich, wie es scheint, nichts $z \mathrm{u}$ tun hat. So sind aus der Abraham-Lotkomposition alle Sagen als sekundäre Wucherungen auszuscheiden bis auf die Hebron- und Sodomgeschichte. Diese beiden Erzählungen sind der letzte Kern, an den sich alle übrigen Einzelsagen kristallisiert haben.

Für unser Problem entscheidend ist die Antwort auf die Frage nach ihrer Herkunft. Die Hebronerzählung ist ohne Zweifel so, wie sie heute lautet, eíne Ortssage. Aber wir müssen weiter forschen, woher die Ortssage ihren Stoff entlehrit hat. Rein_stammesgeschichtliche oder kulturelle Verhältnisse spiegeln sich in ihr nicht wieder, ja sie ist überhaupt nicht bodenständig, wie GUNKEL richtig erkannt hat. Einzelne Züge passen weder zu Hebron noch zum israelitischen Wesen ${ }^{3}$ und legen daher die Annahme nahe, daß die Sage aus der Fremde eingewandert und erst später in Hebron lokalisiert worden ist. Wichtiger als das Ursprungsland aber ist die Bestimmung des literarischen Charakters der Erzählung, die als Vorläuferin der Hebronsage zu gelten hat. Entfernt man aus dieser alle Namen und alles Lokalkolorit, so lautet sie in Kürze etwa so: „Als Olim König war, wandelten einst drei Götter auf Erden, um sich mit eigenen Augen nach den Dingen dieser Welt umzuschauen.

I Das ist einst im Gegensatz zu heute, wo man meist von Jerusalem zur Jordan. ebene hinabsteigt, die Hauptstrabe gewesen. Auf ihr wandernd sollen auch die Israeliten nach dem Buche Josua das Westjordanland erobert haben.

2 Gen $33_{20} 35_{4} ; 28$ 10 ff. 35 Iff.

3 GuNKII $^{3}$ S. 200 verweist besonders auf, das Fehlen des Weines, auf das zu Tische Liegen und auf die Dreizahl der übermenschlichen Wesen. 
Während sic unter der Glut der Mittagssonne seufzten, kamen sie zu einem Zclt unter ciner schattigen Terebinthe, die zu kurzer Rast einlud. Lin altes, kinderloses Ehepaar, das dort wohnte, nahm sie freundlich auf und bewirtete sie freigiebig, so daß sie neugestärkt den Weg fortsetzen konnten. Zum Dank dafür erfüllten sie den Herzenswunsch der beiden Alten und schenkten ihnen übers Jahr einen Sohn". Wer diese Erzählung liest, wird sie sofort in die Gattung der Märchen einreihen. In der Tat sind uns solche Märchen überliefert ${ }^{x}$. Die Hebrongeschichte ist kein Märchen mehr, sondern eine Sage, weil der Stoff an eine bestimmte Person und einen festen Ort gebunden, auch schon teilweise auf eine höhere Stufe gehoben ist: zwar wandelt die Gottheit noch auf Erden, genau so wie im Märchen, aber das Motiv des Wunsches ist nicht mehr in der ursprünglichen Reinheit erhalten. Denn dem Gott des Märchens ist eigentümlich, daß er dem zu Belohnenden eine, oder gewöhnlich drei, Bitten freistellt. In der Hebronsage jedoch durchschaut das himmlische Wesen die beiden Alten und weiß im Voraus, was sie wählen-werden. Die Idee der Gottheit ist also bereits erhabener geworden. Weil das Motiv der Hebronerzählung, die Bewirtung des unerkannten Gottes, überall und nirgends zu Hause ist ${ }^{2}$, darf man vermuten, daß es dem Märchen entnommen ist. Denn das Märchen, das im Gegensatz zur Sage weder an einen geographischen Ort noch an eine historische Person geheftet ist, kann als herrenloses Gut von Volk zu Volk wandern und bald hier, bald dort, teils in alter, teils in neuer Form auftauchen, was bei der Sage ausgeschlossen ist 3 .

Auch die Sodomerzählung ist ihrer gegenwärtigen Fassung nach eine Ortssage, die am Toten Meere haftet. Aber hier schimmert der ursprüngliche Märchencharakter des Stoffes noch viel deutlicher durch als in der Hebronsage. Zunächst begegnet uns wiederum das schon bekannte Motiv von der Bewirtung der himmlischen Wesen, die diesmal mit der Rettung aus dem kommenden Verderben belohnt wird. Ein zweites in Orient und Okzident weit verbreitetes Märchenmotiv ist die Geschichte von der zerstörten Stadt, die wegen des Frevels ihrer Bewohner durch

I Vgl, die Zitate bei GunkeL33 S. I94.

2 Die Gastfreundschaft gilt als eine hohe Tugend nicht nur im Orient, sondern überall in primitiven Verhältnissen. Sie sinkt erst im Werte bei sogenannter Kultur.

3 Mancherlei Material bei GunkeL ${ }^{3}$ S. 194. 200. Gunkel hat richtig das Märchen als Parallele zur Hebronsage herangezogen und damit wieder einen Schritt vorwärts zur Lösung des Problems getan. Man muß aber, wie mir scheint, noch weiter gehen und die Hebronsage direkt von einem bestimmten Märchentypus aus zu verstehen suchen. 


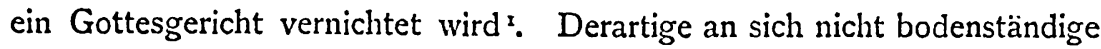
Erzählungen sind dann lokalisiert worden, mit besonderer Vorliebe an schaurigen Stätten, die ein solches Ereignis als wahrscheinlich vorspiegeln. Der moderne Forscher wird sich natürlich hüten, die Sage von Vineta als Nachklang historischer Begebenheiten aufzufassen und etwa die Lage der versunkenen Stadt durch Taucher feststellen zu lassen. Bei der Erklärung der Sodomsage aber ist dieser wissenschaftlich veraltete Rationalismus noch immer nicht ganz überwunden ${ }^{2}$. Sobald einmal klar erkannt ist, daß hier ein Märchenmotiv vorliegt, ist jede geologische Deutung von vornherein als verfehlt abzulehnen 3 . Echt märchenhaft ist die Vorstellung von der Gottheit, die auf Erden wandeln muß, um sich persönlich von dem Unrecht der Menschen zu überzeugen, die im Dunkel der Nacht ungeht 4 und nicht duldet, daß man ihr Geheimnis belauscht ${ }^{5}$. Wer es dennoch tut, wird zur Strafe in Salz verwandelt ${ }^{6}$.

I Eine Fülle von Literatur bei GuNKeL ${ }^{3}$ S. 214. Einer meiner Schüler, Herr stud. theol. OTto SCHRÖDER, macht mich noch aufmerksam auf U. JAHN, Volkssagen aus Pommern und Rügenz. Berlin 1889. Nr. 223, 249, 256, 293 und P. G. Heins, Seespuk. Leipzig 1888. S. $168 \mathrm{ff}$. Vgl. ferner v. d. LEYen, Deutsches Sagenbuch IV S. $234 \mathrm{ff}$.

2 Die rationalistische These ist mit großem Scharfsinn und bestechender Ortskenntnis erneuert worden von DALM.IN (im Palästina-Jahrbuch, Band IV, S. 77 ff.), der annimmt, daß die Städte durch eine „Umkehrung“ zerstört seien, während ihr Gebiet durch die immer höher steigende Flut des Toten Meeres allmählich versalzt worden sei. Weil die Existenzbedingungen sich ānderten, seien die Orte nicht wieder aufgebaut worden.

3 Der sagenhafte Charakter der Erzählung erhellt besonders deutlich aus 13 roff., wo überhaupt das ganze Tote Meer als noch nicht existierend vorausgesetzt wird. Es ist nur vom "Jordangau" die Rede, ein Ausdruck, der das Tote Meer nicht mit umfaßt. Sehr bezeichnend ist auch der Vergleich der Landschaft mit dem "Jahwegarten", dem Paradies!. Wenn die angeblich in jener Gegend zerstörten Städte Namen haben, so ist das kein Beweis für historische Erinnerung; denn auch Vineta, Stavorn u. a. haben Namen, die wer weib' woher stammen mögen.

4 Viele Parallelen bei GunkEL 3 S. 211.

5 Als Grund für das an Lot ergangene Verbot, sich nicht umzusehen, gilt die Absicht der Gottheit, sich bei ihrem geheimnisvollen Tun nicht belauschen zu lassen. Diese Anschauung hängt ursprünglich mit der Zauberei zusammen: Was im Zauber vor sich geht, ist so schrecklich und gefährlich, dà b derjenige, der es wahrnimmt, von ihm vernichtet wird. Darum muß auch der Zauber, wie im Märchen oft befohlen oder erzählt wird, durch rückwärts geworfene Gegenstände vollzogen werden. Vgl. WUNDT, Völkerpsychologie II, 3. S. 94. Beispie!e ebenda Anmerkung 3.

6 WUNDT, Völkerpsychologie II, 3. S. 94 fügt mit Recht zu dem objektiven Mo. ment, wonach geòlogische. Formationen an menschliche Figuren erinnern, noch das subjektive, die psychologische Erstarrung (vgl. I Sam 25 37) infolge der schauerlich-geheimnisvollen Vorgänge, die das menschliche Auge sieht. - Eine Parallele zur Verwandlung in eine Salzsäule auch bei Elisabet SKLAREK, Ungarische Volksmärchen. Leipzig rgoI. Nr. 2: "Glückes Glück" (Variante zum "treuen Johannes"; weiteres Material ebenda Anmerkung S. 288). 
Mit der israelitischen Idec von Jahwe haben diese Züge nicht das Mindeste $z u$ tun, sondern sie sind erst später auf ihn übertragen worden. Es ist nicht unwichtig $z u$ beobachten, wie die Sodomsage, der Hebronsage völlig entsprechend, ebenfalls noch deutliche Spuren fremder Herkunft aufweist; denn zum ersten ist von der Bildung des Toten Meeres, die man erwartet, nicht die Rede, zum andern hört man von Schwefel ${ }^{z}$ und Feuerregen und vom Rauch eines Schmelzofens, was zum Toten Meere nicht paßt, sondern vom Vulkan hergenommen ist ${ }^{2}$. So zeigt sich auch hier derselbe ,literarische" Vorgang, wie das ursprünglich freischweifende Märchen eingefangen und dann als Ortssage an eine bestimmte Lokalität festgebunden wird.

Ist diese Rekonstruktion der literarischen Geschichte, die vom Märchen über die Sage zur Sagenkomposition führt, richtig, so ist damit auch der Ort gegeben, um die Namen Abraham und Lot unterzubringen. Sie gehören der zweiten Stufe, der Einzelsage, an, die dem Märchen noch verhältnismäßig nahe steht, und sind weiter nichts als Personennamen, an die der herrenlose Stoff geheftet wird. Man kann sich das am besten an unseren Märchen klar machen, die ja bisweilen auch mit gewissen Namen unlöslich verknüpft sind. Wie für die jeweiligen Stoffe "Hans und Gretel" oder "der treue Johannes" typisch sind, so $\mathrm{da} \emptyset$ niemand daran denkt, andere Namen dafür einzusetzen, so war bei den israelitischen Erzählern der Name Abraham gebräuchlich, wenn die Geschichte von der Bewirtung der unerkannten Gottheit vorgetragen wurde, während man den Namen Lot mit der Erzählung von der „Umkehrung der Städte" zu verbinden pflegte. Die Frage, warum man gerade von Abraham und Lot redete, ist ebenso $\mathrm{zu}$ beantworten wie die andere, warum man für das betreffende Märchen Hans und Gretel bevorzugt hat: weil diese Eigennamen sehr geläufig waren in der Zeit, wo die Erzählungen zu Typen geprägt wurden ${ }^{3}$. Später sind sie, wie das bei Personennamen

× Vgl. in dem eben genannten Märchenbuch Nr. I: „Der Königssohn, der sich nach der Unsterblichkeit sehnte“, kehrt zur königlichen Residenz zurück. „Er geh näher darauf $z u$, und da war ein Schwefelsee aus ihr geworden, der mit blauen Flammen brannte wie guter Pflaumenbranntwein" (S. 12).

2 Näheres bei GunkeL ${ }^{3}$ S. 215 f.

3 Auch wenn der Name Abraham ursprünglich babylonisch sein sollte, wird es doch kaum erlaubt sein, daraus zu schließen, daß der Stoff des Märchens und der Name dès Märchenhelden aus Babylonien nach Palästina gewandert sei. Denn erstens pflegt bei innerer Aneignung des Stoffes der fremde N2me sofort durch einheimische ersetzt zu werden. Zweitens wäre bei jener Hypothese schwer begreiflich, wie Abraham zum Ahnherrn gerade der Hebräer werden konnte. 
oft geschieht, aus der Mode gekommen, während die Sagenerzähler an den alten Namen feșthielten, ja immer mehr Geschichten auf sie häuften. Man sieht daraus zugleich, in eine wie alte Zeit die Eigennamen Abraham und Lot zurückreichen müssen, und begreift daher un so leichter, dab sie zu Stammvätern umgedeutet werden konnten. Wenn Lot, wie bereits vermutet worden istr, erst nachträglich zum Ahnherrn von Moab. und Ammon gemacht werden konnte, so dürfte dieselbe Annahme auch für Abraham auf keine Schwierigkeiten stoßen. Die Umwandlung des Märchens zur Sage, das darf man mit großer Bestimmtheit behaupten, ist in Hebron oder vielleicht noch richtiger in der. Wüste Juda ${ }^{2}$ erfolgt; denn dort und nur dort hatten die Erzähler ein Interesse daran, die eine Geschichte mit dem Baume von Mamre, die andere mit dem Toten Meere zu verbinden. Dorthin weist auch die Sage von Isaaks Opferung, die als Kultussage von Jeruel ${ }^{3}$ in der Wüste Juda lokalisiert ist. Während Jakob erst durch eine spätere Sagen-Verknüpfung in die Genealogie Abrahams eingefügt worden ist, gehört Isaak von Hause aus mit Abraham zusammen: er hat keine selbständige Existenz gehabt, sondern ist immer "der Sohn seines Vaters" gewesen. So erklärt sich am einfachsten, daß die Geschichten beider in derselben Gegend spielen: in der Wüste Juda und dem Negeb. Später hat Isaak einen Halbbruder erhalten in Ismael, von dem die älteren Erzählungen noch nichts wissen. Überall wo uns Ismael in der Genesis begegnet, scheint er die Personifikation des gleichnamigen Stammes zu sein. 'Über dies'ungleiche Paar sich zu wundern, liegt kein Anlaß vor, da die israelitische Sagenwelt mancherlei Parallelen aufzeigt. Wie Isaak neben Ismael steht, so Abel neben Kain, Thamar neben Juda, Dina neben Simeon und Levi. In diesen Paaren ist immer nur der zweite Teil als Personifikation eines Stammes aufzufassen und zugleich als der jüngere gegenüber dem ersten zu betrachten, wie die genauere Analyse lehrt. Da die Stammesnamen ursprünglich und auch später noch Personennamen sind, so empfindet der Israelit die Ungleich-

I Vgl. Ed. Mérer, Israeliten S. 26I, 3II. Allerdings tut er dies nur faute de mieux, weil er bei Lot nichts (scil. Mythologisches oder Stammesgeschichtliches) ermitteln kann.

2 Nirgendwo wird vorausgesetzt, daB Abraham in Hebron selbst weilt, sein Zelt steht unter dem Gottesbaumi östlich von IJebron (der nach dem PiLger von BORDEAUX $2 w e i$ römische Meilen $=$ drei $\mathrm{km}$ entfernt ist). Von der Wïste Juda, aber nicht von Hebron aus, blickt man über das Tote Meer hinüber in die Gegend von Moab und Ammon.

3 Vgl. den Beweis bei Gunkel 3 S. 241. 
heit inncrhalb der Paare nicht so wie wir, die wir historisch geschult sind und $\mathrm{zB}$. bei Ismael sofort den Stamm vor Augen sehen ${ }^{z}$.

b) Úberblickt man die Genesis als Ganzes, so zerfällt sie in drei Teile, die religionsgeschichtlich wie literargeschichtlich toto coelo voncinander abzuweichen scheinen. In der Mitte stehen Kap. $12-36$ als Sagen, bei denen der spezifisch israelitische Charakter durchaus überwiegt. Erst bei genauerem Zusehen erkennt man, dab sie im letzten Grunde einen fremden Kern enthalten, den ich als internationalen Märchenstoff bezeichnet habe. Diese Erzählungen sind von zwei Gruppen eingerahmt, deren ausländischer Ursprung trotz der israelitischen Übermalung längst durchschaut ist. Die These, daß Kap. I-I I Mythen mit stark babylonischem Einschlag sind, bedarf heute keines Beweises mehr. Wie auch diese Mythen aus Märchenstoff entstanden und aufgebaut sind, das hoffe ich bei anderer Gelegenheit zeigen zu können². Weniger allgemein zugestanden ist wohl das ägyptische Gepräge, das Kap. 37-50 aufgedrückt ist. Hier ist die Herkunft des Materials aus der Märchenliteratur am deutlichsten zu konstatieren. Darum mag die Josephgeschichte.der Besprechung der Jakoberzählungen vorangehen.

Mit Recht ist der mehr oder minder geschickte Versuch 3, die Josephsage in Stammessage aufzulösen, als verfehlt abgelehnt worden: „Sehr große und bedeutsame Partien der Sage sind es, die weder historische noch ätiologische Grundlage $\mathrm{zu}$ haben scheinen: so besonders Josephs Schicksale in Ägypten, bei denen Joseph nichts als eine Privatperson ist, und in denen jeder Gedanke, daß Joseph eigentlich ein Stamm sei, ganz unmöglich sein würde" 4. Eine klare Antwort aber, woher der Stoff gekommen ist, wenn er weder mythischen 5 noch stammesgeschichtlichen

× Gunkel hat das Richtige instinktiv empfunden, wenn er neben dem Stammes: geschichtlichen einen rein "novellistischen" Stoff in der Dina- und Thamarsage unterscheidet (2 S. 329, 369). Er setzt ,novellistisch" stets in Anführungsstriche und fügt an der letzten Stelle als erklärendes Attribut hinzu: „für uns undurchsichtig“. Mittlerweile hat er in der Deutschen Rundschau 1905 S. $68 \mathrm{f}$. auf das Buch Ruth und den Isismythus als Parallelen zur Thamarsage aufmerksam gemacht. Der Stoff aber ist nicht dem Mythus, sondern dern Märchen entlehnt und von dort aus in den Mythus und in die Sage gelangt. Entscheidend ist die Tatsache, daß es sich um internationales Gut handelt.

2 Die prinzipielle Erkenntnis verdankt die Wissenschaft dem genialen Scharfblick WUNDTs in seiner Völkerpsychologie.

3 Hier ist besonders Steuernagel zu nennen.

4 GUNKEL2 S. 352. Dort auch Ansätze zur richtigen Erkenntnis.

5 Die wilden Phantasien der Astralmythologen zu widerlegen, möge man mir erlassen, da die Polemik völlig unfruchtbar ist. 
Ursprungs sein soll, ist noch nicht gegeben, obwohl sie nahe genug liegt. Vergegenwärtigen wir. uns den Aufriß der Josephsage: Der jüngste Sohn seiner Eltern wird von den Brüdern, die ihn hassen, in eine Grube geworfen und dann als Sklave in ein fernes Land verkauft, wo er nach allerlei Abenteuern zu Reichtum und Ehren gelangt. So kommt es, daß die Brüder, ohne es zu wissen, seine Hilfe in Anspruch nehmen, aber nachdem sie von ihm erkannt worden sind und seine Verzeihung erhalten haben, z.u ihm in die Fremde ziehen und sein Glück teilen. So wie die Josephsage heute vorliegt, ist sie von GUNKEL richtig als Novelle definiert worden; ich würde noch genauer sagen Abenteuernovelle. Als ihr Vorläufer darf das Glücksmärchen gelten, von dem sie sich durch das Abstreifen der phantastischen Züge, durch die Bereicherung mit kulturhistorischem Gut und durch die Vertiefung der Psychologie unterscheidet. Läßt man alles Beiwerk außer Acht und betont nur die konstitutiven Elemente der Erzählung, so kann man ein westslawisches Märchen als Parallele anführen, das denselben Aufriß hat: Michael wird von seinem Oheim, der ihn töten will, in eine Grube gebracht und dort im Stich gelassen. Als er der Gefahr glücklich entronnen ist, wandert er in die weite Welt, wird von einem Schloßherren freundlich aufgenommen und nach dessen Tode zum Erben der gesamten Güter eingesetzt. Eines Tages kommt der unterdes verarmte Oheim, um zu betteln, aufs Schloß, wird von Michael sofort erkannt und dort behalten. Auch ein älterer Bruder Michaels wird geholt, 'um sein Glück zu teilen ${ }^{x}$. So ist das Gerippe der Josephsage dem Typus der Glücksmärchen verwandt.

Aber auch das Fleisch und Blut, mit dem man das Gerippe umkleidet hat, stammt zum größten Teil aus dem Märchen. Wir sind heute in der angenehmen Lage, diese Behauptung wenigstens an zwei Beispielen schwarz auf weiß rechtfertigen zu können. Die Erzählung von der verleumderischen Ehebrecherin, die an sich nichts Märchenhaftes hat, ist auch in der ägyptischen Literatur überliefert und zwar in einem Zusammenhange, der ein unverkennbares Märchengepräge trägt ${ }^{2}$. Dasselbe gilt von der Geschichte des versteckten Bechers in den Kornsäcken der Brüder Josephs; in dem ägyptischen Märchen von der ,wunderbáren Geburt der. Kinder des Re" wird von drei Königskronen erzählt, welche die himmlischen Paten in einem Gerstensack verbergen. Und wie jentr Becher, aus dem Joseph 7.u weissagen pflegt, geheime Zauberkräfte hat, so verstehen diese Kronen zu singen, musizieren, tanzen und

I WenzIG, Westslawischer Märchenschatz. Leipzig 1857. S. $26 \mathrm{ff}$.

2 Vgl. Gressuani, Texte und Bilder, Band I, S. 223 f.

Zeitschsift f. d. alttest. Wiss. Jahrg. 30. 1910 . 
kreischen, kurz allerlei Dinge, an denen sich das Herz eines Königs erfreut ${ }^{3}$. Märchenhaft ist ferner die Gestalt des Traumdeuters, dessen Orakel sämtlich eintreffen ${ }^{2}$, und der sich durch diese Kunst vom Sklaven zum mächtigsten Manne nach dem König emporhebt. Hier haben wir indessen schon ebenso wie in der Gestalt des Getreideaufsehers, die unlängst durch den Janhamu der Amarnabriefe erhellt worden ist, und in manchen anderen Einzelheiten die Einflüsse der ägyptischen Kultur vor uns, welche die Erzählung über das ursprüngliche Glücksmärchen hinausheben und sie in einer für den Kulturhistoriker unschätzbaren Weise bereichert haben. Viele Elemente der Josephsage sind zweifellos ägyptischen Ursprungs; bei den konstitutiven Bestandteilen ist keine sichere Entscheidung über die Herkunft möglich. Jedenfalls aber ist eine Vergleichung. der ägyptischen Märchen mit der Josephsage nach Form und Inhalt ein dringendes Bedürfnis. Vermutlich wird sich dann herausstellen, daß die israelitischen Erzählungen den ägyptischen weit überlegen sind durch den in ihnen waltenden Vorsehungsglauben.

Joseph ist anfänglich nichts weiter gewesen als der Held des. der Novelle zugrunde liegenden Glücksmärchens, wie Michael in der zitierten westslawischen Geschichte. Später ist er zum Stammvater Ephraims und Manasses geworden und in die Genealogie Jakobs eingereiht. Den Antrieb dazu gab wahrscheinlich die Tatsache, daß die beiden Stämme Ephraim und Manasse ebenso wie Joseph auf ihren Wanderfahrten nach Ägypten verschlagen wurden 3. Das Stammesgeschichtliche, das dem märchenhaften Stoff eingefügt ist, fällt als späterer Fremdkörper deutlich heraus und kann entfernt werden, ohne das Gewebe des Ganzen zu zerstören. Es gehört nicht zum Fundament, sondern zum oberen Stockwerk. Die Umdeutung der privaten Erlebnisse in die eines Stammes, die wohl schon von den späteren Sagenerzählern und dem Sammler vollzogen wurde, ist sekundären Ursprungs. Anfangs aber handelt es sich nur um einen hebräischen Jüngling namens Joseph, der als Sklave nach Ägypten verkauft wurde und dort allerlei Abenteuer im Stil des Märchens erlebte.

c) Um die Gestalt Jakobs sind zwei Sagenkränze geflochten, von denen der eine mit Esau, der andere mit Laban verknüpft ist. Da der Jakob-Esau-Sagenkranz den Rahmen bildet, in den der Jakob-LabanSagenkranz-eingestellt ist, so wird man jenen a priori-für den älteren

I Ebenda S. $222 \mathrm{f}$. $2 \mathrm{Zu}$ den sieben fetten und mageren Jahren ebenda S. 233.

3 Daß Ephraim und Manasse, als der Kern des späteren Volkes Israel, in Ägypten gewesen sind, steht mir als historische Tatsache aus anderen Gründen fest. 
halten dürfen ${ }^{x}$. Beide haben in gewisser Beziehung einen völlig voneinander abweichenden Charakter. Die Jakob-Laban-Geschichte ist fast ausschließlich Kultursage (s. u.). Ortsnamen, wie der Gileads, spielen nur eine Nebenrolle. Außer der Verschlagenheit, die den Hirten auszeichnet, wird auch die Körperstärke Jakobs verherrlicht (28 II 29 Io 3 I 45). Doch überragt sie niemals, so ungewöhnlich sie sein mag, das menschliche Maß. Die Religion ist verhältnismäßig hoch entwickelt. Weder Gott noch seine Engel erscheinen leibhaftig auf Erden, sondern offenbaren sich im Traum. Das ist die Anschauung, die der späteren israelitischen Religion entspricht. Eine ganz andere Luft weht uns aus den JakobEsau-Sagen entgegen. Zunächst trifft man Ortssagen, die eine seltsame Gottesvorstellung enthalten und dem Jakob übermenschliche Kräfte beilegen. Mahanaim hat seinen Namen daher, weil Jakob dort auf das "wilde Heer" gestoßen ist ( 32 2f.). Wenn dies in Mahranaim gelagert haben soll, so muß es leibhaftig auf der Erde gewandert oder durch die Luft geritten sein, wie es das Märchen erzählt. Man darf diesen Unterschied der Gottesauffassung nicht etwa auf zwei Quellenschriften zurückführen. Er ist sehr viel älter und eine nicht loszulösende Eigentümlichkeit zweier, voneinander abweichender Erzählungstypen.

Noch charakteristischer ist die Ortssage von Penuel (32 23-33), besonders interessant deshalb, weil sie $z \mathrm{u}$ den wenigen israelitischen Ortssagen gehört, die nicht mit einem Heiligtum verbunden sind. Ihr Stoff ist den Zaubermärchen entlehnt. Das Thema ist der Ringkampf des Märchenhelden mit einem übermenschlichen Kobold, dem er den Zaubersegen entreißt. Durch die Lokalisierung an einer Furt ist aus dem Kobold speziell ein Flu§dämon geworden, der die Furt hütet und nicht duldet, daß jemand,ohne ein Geschenk oder eine Opfergabe den Fluß durchschreitet ${ }^{2}$. Jakob hat es gewagt, um die mitternächtige Stunde mit seinem Vieh und seiner Familie die Furt zu passieren. Als alles gluicklich hinübergebracht und er noch allein zurückgeblieben ist, springt plötzlich aus dem Oleandergebüsch des Jabbok der Flulneck auf ihn zu, ringt mit ihm und will ihn würgen, weil er die Kühnheit gehabt hat, die mitternächtige Ruhe des Dänons zu stören. Unentschieden wogt der Ringkampf hin und her. $\mathrm{Da}$ aber die Morgenröte herannaht, so verletzt

I Zu demselben Urteil ist Gunkez2 S. 259 gelangt, obwohl er einen anderen Weg eingeschlagen hat.

2 Eine Fülle ethnologischen Materials bei Frazer in den Anthropological Essays, presented to E. B. Tylor. Oxford, 1907. S. $136 \mathrm{ff}$. Er hat die Erklärung dieser Er. zählung sehr gefördert, wenn ich auch nicht alle Folgerungen mitmachen kann. 
der Dämon, der wie die Götter und Elfen des Märchens bei Sonnenaufgang verschwunden sein mul, die Fechterregeln und schlägt dem Jakob auf die Hüfte, daß sie verrenkt wird ${ }^{x}$. Dieser aber ist kräftig genug, den Neck auch jetzt noch nicht loszulassen, und kehrt den Spieb um. Jetzt fordert er, und der Dämon muß gehorchen, wenn er noch vor Sonnenaufgang loskommen will. Jakob verlangt den Namen des Dämons zu wissen. Vielleicht wurde einmal erzählt, da\ dieser seinen Namen verriet. Seitdem war er Jakob untertan; dieser brauchte nur zu rufen, so war der Geist da, genau wie im Märchen. Nach dem jetzigen Stande der Erzählung begnügt sich Jakob freilich mit einem Zaubersegen : er erhält den Namen "Gottesstreiter" und mit dem Namen natürlich auch die in ihm verborgene Zauberkraft. Seitdem ist er Menschen und Göttern überlegen. An die Sage ist noch ein ätiologischer Kultritus gehängt. Daher essen die Israeliten keine Hüftmuskeln mehr. Denn sie wissen, $\mathrm{da} ß$ der Hüftmuskel gelähmt wird, wenn man auf den Nerv schlägt. Wer einen gelähmten Hüftmuskel ißt, wird selbst gelähmt und würde hinken ${ }^{2}$ wie Jakob nach dem Ringkampf mit dem Furtdämon des Jabbokflusses. Wer diesen märchenhaften Charakter der Penuelsage einmal klar erkannt hat, wird sich hüten, daraufhin Jakob für einen depotenzierten Riesen oder gar Gott zu erklären. Im Märchen kämpfen auch Menschen mit Dämonen und Ungeheuern.

Überwiegt hier die Kraft Jakobs, so in der Esausage seine Schlauheit. Stärke und Klugheit, das sind ja die typischen Eigenschaften des Märchenhelden, weil sie das Ideal des primitiven Menschen sind. Jakobs Gegenstück ist der dumme Esau. Es ist ja längst erkannt und betont worden, von Gunkel, Ed. Mever, Eerdmans u. a., daß Esau erst spät und künstlich mit Edom identifiziert worden ist. Die Stammessage ist auch hier nicht das Fundament, sondern das oberste Stockwerk. Allerdings hat man noch nicht alle Konsequenzen daraus gezogen 3 und namentlich die Jakob-Esausage nicht ihrem Ursprunge nach genügend

I So wenigstens nach der deutlichen Aussage des Textes. Ich bezweifle, ob je erzāhlt wurde, Jakob habe den Hüftnerv des Gottes geschlagen. Die Varianten der beiden Rezensionen sind sonst ganz geringfügig. Der ätiologische Kultritus muß jedenfalls mit dem Hinken Jakobs zusammenhangen.

2 Auch dafür hat Frazer a. a. O. einen interessanten Beleg aus dem Gebiet der nordamerikanișchen Indianer beigebracht: Die Cherokesen essen den Kniekehlenmuskel des erlegten Wildes nicht, entweder weil sich sonst die Sehne des Menschen zusammenziehen würde oder weil er sonst nicht laufen könnte.

3 So hält ĖD. MEYER, Israeliten S. 329, 387 die Edomiter urm Esaus willen für ein Jägervolk. Aber wo ist Edom sonst so geschildert? 
erklärt. Den richtigen Weg hat GuNkEL gewiesen, der als ältestes Thema den Wettstreit zwischen dem Hirten und dem Jäger vermutet ${ }^{x}$. Solche Karrikaturen der verschiedenen Stämme und Stände entsprechen dem Horizont primitiver Menschen, sind darum in der alten Zeit sehr beliebt gewesen und begegnen noch im modernen Orient ${ }^{2}$. Die Jakob-Esausage ist in einem Hirtenstamm geprägt, da der Jägerstamm verspottet wird. Dem Hirten gilt der Jäger als leichtsinnig und dumm, weil er von der Hand in den Mund lebt und sich nicht um das Morgen kümmert. Er belustigt den Hirten, weil seine Kleider schon von fern nach dem Waidwerk duften. Dem Hirten, der sein Zelt hat, ist es unbegreiflich, wie der Jäger auf dem Felde umherschweifen und unter freiem Himmel schlafen mag. Daher vergleicht der Hirt sich mit dem richtigen, ordentlichen Menschen, den Jäger aber mit den wilden, unvernünftigen Tieren 3. Darum eben muß Esau über und über behaart sein wie ein zottiger Ziegenbock. Mag sich dies auch aus der vorauszusetzenden Karrikatur erklären, so ist doch die Nachahmung Esaus durch Jakob in Kap. 27 nicht ohne weiteres verständlich. Vielleicht darf man vermuten, daß diese Erzählung durch bestimmte Riten des Jägerstandes angeregt ist. Es ist eine uralte, überall in der Welt verbreitete Sitte, die Gestalt des Gottes zu imitieren. Am bekanntesten sind die Kultbräuche, bei denen Vegetationsdämonen mit Masken, Bildern und Gewändern dargestellt werden, um durch diesen Zauber die Fruchtbarkeit des Bodens zu gewährleisten. So waren die Tänzer der Satyrspiele mit- Ziegenfellen und Bocksschwanz bekleidet. Solchen Mimus haben auch die Semiten geübt: Es sei an die babylonischen Priester des Fischgottes erinnert, die in eine Fischhaut gehüllt waren 4 , an die mit Schaffellen behangenen Priester der Schafgöttin auf Kypros5, an die Tiermasken der christlichen Araber, die den frommen Bischöfen Sorge bereiteten ${ }^{6}$, in Israel vielleicht an den Theraphim 7 . Die

I GUNkEL2 S. 279.

2 Diese Verspottung der verschiedenen Stände und Volksstämme ist ein geläufiges Thema der Schattenspiele (Puppentheater, türkišch Karagöz) in Kairo.

j Vgl. die in Märchen vorkommende Gestalt vom "behaarten Mann", der "über und übet mit Haaren bedeckt ist, fast wie ein unvernünftiges Ticr"; vgl. Ungarische Volksmärchen, ausgewählt und übersetzt von EliSAbET SKLAREK. Leipzig 1901. S. 130ff. Bekannt ist ferner das deutsche Märchen vom „Eisenhans" (GRins No. 136). Weitere Parallelen bei Rernhold Köhlegr, Kleinere Schriften. Weimar 1898 Band I, S. 333 Anm. 1. 4 Gressurasin, Texte und Bilder, Band II, Abb. 100.

5 W. R. SxItri, Religion der Semiten S. 335. 6 Ebenda S. 335 Anm. 760.

7 Wenn der Theraphim eine Gesichtsmaske war, was I Sam 19 durch den Scherz Michals nahegelegt wird, und der Ephod das entsprechende Kleid: Beim Orakelerteilen kündete der Priester in der Maske und dem Gewande der Gottheit die Zukunft. IVie 
zauberhaften Tänze und Darstellungen sind früh wie beim griechischen Satyrspiel zur Burleske und zum Mummenschanz herabgesunken. Nun bleibt noch dic merkwürdige Parallele mit Usoos, die man oft herangezogen hat, dic aber gerade in diesem Zusammenhang eine besondere Bedeutung gewinnt ${ }^{x}$. Usoos war auch ein Jäger; er lehrte die Menschen aus den Fellen der erlegten Tiere Kleider zu fertigen und das Blut an die heiligen Steine zu streichen. Man darf daraus schließen, daß in seinem Kultus die Priester bei der heiligen Handlung die Felle der dargebrachten Gazellen- oder Hirschböcke trugen. So empfiehlt sich auch von hier aus die Identifikation Esaus mit Usoos ${ }^{2}$, doch hat man keinen Grund, Esau für einen ursprünglichen Gott zu halten. Viel näher liegt es, beide auf die gemeinsame Urgestalt des Jagddämons oder des Bocksatyrs zurückzuführen 3, der für PHILO Byblios zum Gott emporgestiegen, für die

dem auch sei, jedenfalls wurde der Theraphim auch zu Zauberzwecken verwandt: Jakob verscharrt ihn und die Ohrringe unter dem Gottesbaum bei Sichem ( $35_{2} \mathrm{ff}$; daher "Zauberbaum" I2 6). Sie vertraten gewissermaßen die Amulette oder Reliquien, die einen

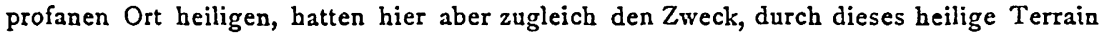
einen Schutzwall gegen die verfolgenden Feinde zu bilden: „Es lag aber ein von Gott gewirkter Schrecken auf den Städten, so daß man die Söhne Jakobs nicht verfolgte" (355). Die beste Parallele dazu erzählt Olympiodor (FHGr IV S. 63 fr. 27): Zur Abwehr von Feinden waren bei der illyrischen Grenze drei silberne Bildsāulen, die Hānde auf dem Rücken gefesselt, am heiligen Orte vergraben, so dab ihr Gesicht nach Norden gewandt war. Als man sie aus der Erde nahm, brachen die Feinde ein.

1 PhILo ByBl. fr. 2, 7 f.

2 Gegen die Identifikation von Usoos mit Usû (AIt-Tyrus) vgl. ED. MEYer, Israeliten S. 278 Anm.

3 Für diese These läßt sich geltend machen: 1. Esau wird als ein שיר ,ein Bocksdämon" geschildert. 2. Die Kleider, die wohl späterer Ersatz für das ursprünglich angewachsene Fell sind, duften wie die Tierfelle. 3. Esau ist ein "Mann des Feldes", während Jakob „in Zelten wohnt"“. Es scheint fast, als hätte Esau überhaupt keine Wohnung wie der Bockssatyr, der durch die Felder streift, wie Eabani, dessen Gestalt noch deutlicher die des Vegetationsdämons bewahrt hat. 4. Wie für Eabani der gierige Liebesgenuß, so ist für Esau die gierige Gefräßigkeit bezeichnend. Man müßte dann allerdings annehmen, daß das Wortspiel auf Edom erst später hinzugefügt ist. Das macht keine Schwierigkeit, im Gegenteil, wie sollte man wohl darauf verfallen sein, ge. rade die Edomiter für besonders gefrāßig auszugeben? Die Israeliten schlangen gewiß nicht minder, wie es noch heute die Araber in entsetzlicher Weise tun. Die Satyrn verkörpern das Triebleben der Natur, vor allem den Zeugungstrieb, daher sind sie zu beliebten Motiven der obszönen Kunst geworden. 5. Die Dummheit ist für Esau so charalteristisch, wie für den mittelalterlichen Teufel, der ja auch nur ein verkappter Satyr ist. Esau ist so dumm, daß er die Linsen nicht kennt und den Wert der Erstgeburt nicht zu schätzen weiß. . Immer wird er von Jakob übertölpelt; in der Szene vor Isaak wird seine Unbebolfenheit köstlich gezeichnet. 6. Die Imitation Esaus durch Jakob. - Die Nebeneinanderstellung von Jakob und Esau wäre unter dieser Voraussetzung noch nicht so wunderbar, wie die von Eabani und Gilgameš; denn in diesem Falle steht der ursprüng. liche Vegetationsdämon neben einem von Hause aus historischen König! 
Sagenerzähler in Israel dagegen zur Scherzfigur herabgesunken ist. Ihn mit Edom-Seir zu kombinieren, war später ein köstlicher Schabernack für die guten Freunde und getreuen Nachbarn. Jedenfalls ist dies erst später geschehen, wie aus der Erzählung selbst noch deutlich ersichtlich ist. Denn als Esau-Edom gesegnet wird, da hören wir kein Wort von der Jagd, wohl aber vom "Schwert" (v. 39f.). Demnach war Edom gar kein Jägervolk, wie überhaupt im ganzen Alten Testament weder von einem Jägerstamm noch von einem Jägerstand die Rede ist, wie auch die Araber niemals und nirgendwo Jäger sind ${ }^{x}$. Anders mochte es mit den Phönikern sein, in deren Gebiet der Libanon mit seinem reichen Wildbestande lag. So geht aller Wahrscheinlichkeit nach auch die JakobEsausage im letzten Grunde auf den Stoff eines ausländischen (Kultur-) Märchens zurück.

d) Resultat. Als Vorstufe der in der Genesis gesammelten Sagen erscheinen überall solche Stoffe und Motive, die sich teils direkt in den Märchen anderer Völker wiederfinden, teils als auf der Märchenstufe stehend charakterisieren lassen. Man darf darum die von WUNDT aufgestellte allgemeine These, daß das Märchen der Vorläufer der Sage sei, für das Alte Testament als richtig anerkennen. Zwar sind uns israelitische Märchen im eigentlichen Sinne des Wortes nicht aufbewahrt worden, aber die Verwandtschaft mancher Sagen, wie die von Hebron, Sodom, Penuel, Joseph,-Bileam ${ }^{2}$, mit den Märchen ist noch so groß, daß man sie fast als Kunstmärchen ansprechen darf. Auch in den Erzählungen der historischen Bücher wie in den Sprüchen, Allegorien und Visionen der Propheten 3 sind mancherlei Märchen und Märchenmotive enthalten. Die Israeliten, so darf man daher behaupten, haben wie alle antiken Völker primitive Erzählungen besessen, die man am besten unter dem Namen "Märchen" zusammenfaßt. Diese Annahme macht um so weniger Schwierigkeit, als jetzt ägyptische Märchen bis I800 v. Chr. literarisch nachweisbar sind4: Aber nicht die Vokabel ist das Entscheidende, sondern die Sache.

Mag man dịe primitiven Erzählungen nennen, wie man will, jedenfalls liegt ein besonderer Typus einer literarischen Gattung vor, die ihre eigentümlichen Merkmale hat. Am hervorstechendsten ist der internationale

I So auch SchwöвEL im Palästina-Jahrbuch, Band IV, S. 94.

2 Vgl. dazu meine Ausführungen: Das AT in Auswahl II a: Alteste Geschichtsschreibung und Prophetie S. $60 \mathrm{ff}$.

3 Vgl. GuNkel, Kultur der Gegenwart I, 7. Die orientalischen Literaturen S. 73.

4 Vgl. Gressuran, Texte und Bilder, Band 1, S. 217. 
Charakter des Stoffes, dessen Ursprungsland für uns heutigen Forscher meist nicht oder noch nicht erkennbar ist. Ehe man diese Frage beantworten kann, muß noch unendlich viel Material gesammelt und verarbeitet werden. Vielleicht wird eine künftige Generation klarer sehen als wir. Neben dieser ersten Aufgabe ist die zweite nicht zu vernachlässigen, die freilich erst dann ganz gelöst werden kann, wenn jene erste erfüllt ist, nämlich $z \mathrm{u}$ untersuchen, durch welche Eigenschaften sich die Erzählungskunst Israels von derjenigen der anderen Völker unterscheidet und vor ihr auszeichnet. Denn das darf man von vornherein erwarten, wenn man es auch erst später durch unanfechtbare Beweise erhärten wird, daß bei der geradezu erstaunlichen Erzählergabe der Israeliten jeder Vergleich zugunsten Israels ausfallen wird.

Immerhin läßt sich schon mancherlei folgern, wenn das Prinzip als richtig anerkannt wird. So wenig die Märchen abgeblaßte Mythen sind, so wenig hat man ein Recht, hinter den Sagengestalten mythische Personen zu suchen. Während man früher nur allzu geneigt war, bei einem Vergleich z. B. zwischen dem Gott baiti-ilu und dem Patriarchen Bethuel jenen für ursprünglich und diesen für eine Entartung des Gottes zu halten, wird man heute sehr viel vorsichtiger urteilen müssen. Da das Axiom hinfällig ist, sind auch die daraus gezogenen Schlüsse nicht zwingend. Statt im Bereich der höheren, wird man lieber in dem der niederen Mythologie suchen müssen, statt bei den Göttern vielmehr bei den Dämonen, wenn man die den primitiven Erzählungen entsprechenden Gestalten finden will. Ohne die Fehler der Folkloristen mitzumachen, die gewöhnlich nichts als Folklore, Zauberei, Dämonenglauben konstatieren und alle Anzeichen höherer Religion ignorieren, wird man doch die von ihnen gebotenen Hilfsmittel nicht unterschätzen dürfen, sondern sie noch mehr, als es bisher schon geschehen ist, berücksichtigen müssen.

Ebenso wird man sich hüten, die den Märchen eigentümliche religiöse Gedankenwelt für die Vorgeschichte der Jahwereligion zu verwerten. Denn soweit sie dem Stoff eingeboren ist, trägt sie dieselbe internationale Ursprungsmarke wie das Material, von dem sie unablösbar ist. Gewi@ können neue und höhere Ideen hinzugefügt sein, die als Zeugnis späterer Anschauung sorgfältig $\mathrm{zu}$ beachten sind, aber es ist geradezu auffällig, mit welcher konservativen Zähigkeit besonders die Ortssagen (Hebron, Sodom, Mahanaim, Penuel) die uralten, überall in der Welt verbreiteten Vorstellungen bewahrt haben. Sie haben sich einer organischen Anpassung an die israelitische Religion aufs schroffste widersetz.t. Man braucht fast nur den Namen Jahwes zu streichen, so hat man den ganzen 
Firnis entfernt, mit dem Israel die fremden Gemälde übermalt hat. Die Einwurzelung des Stoffes an einem bestimmten Orte ist offenbar für seine Weiterentwicklung nicht günstig gewesen. Auch die El-Religion, die uns in den Kultursagen lebendig entgegentritt, hat in diesen Ortssagen kaum merkliche Spuren hinterlassen.

3. Unter dem Namen Kultursagen fasse ich alle diejenigen Erzählungen zusammen, in denen das kulturgeschichtliche Milieu der alten Zeit an deutlichsten durchblickt. Um den grundlegenden Unterschied der israelitischen Zivilisation von der anderer Völker zu erkennen, ist ein Vergleich mit der babylonischen Oannessage äußerst lehrreich. Dies Wesen, so wird berichtet ${ }^{x}$, habe den Menschen die Kenntnis der Buchstaben, Wissenschaften und mannigfacher Künste übermittelt und sie Städtebesiedlung, Tempelgründung, Gesetzeseinführung und Landvermessung gelehrt, habe sie über Saat und Ernte unterrichtet und habe den Menschen alles, was zu einem kultivierten Leben gehört, überliefert. Hier ist auf den ersten Blick die hoch entwickelte Zivilisation des babylonischen Staates ersichtlich. Von all diesen Dingen wird in der Genesis nur der Ursprung des Städtebaues erwähnt, aber beide Male (4 I7 I I I ff.) im Anschluß an ausländische Städte. An die Stelle der Tempelgründung sind Altäre, Masseben und heilige Bäume getreten, die ersten primitivsten Gegenstände des Kultus. Ebenso primitiv sind die profanen Künste, über deren Erfindung und Entstehung Israel nachgedacht hat: über die Nahrung von Baumfrüchten und Fleisch, über die Kleidung aus Blättern und Fellen, über. Ackerbau und Weinzucht, "über die Hirten, Schmiede und Musikanten. Während bei den Babyloniern diese Künste auf mythische Gestalten, bei den Griechen auf sagenumwobene Helden, bei den Römern auf die ersten Könige zurückgeführt werden ${ }^{2}$, so bei den Israeliten auf die Väter der Urzeit, begreiflich genug! Da sie selbst im geschlechterrechtlichen Verband leben, an dessen Spitze Familienhäupter und Älteste stehen, so sind ihnen auch für die Vergangenheit nur diese Verhältnisse denkbar und geläufig. Wie sollen sie, von Königen erzählen, die sie nicht kennen oder wenigstens nicht schätzen? Die Persönlichkeit ihrer Götter ist noch nicht ausgebildet und erhaben genug, um auch die Fortschritte der Zivilisation von ihnen abzuleiten. Und endlich, Helden besitzen sie nicht, da sie die Friedfertigkeit höher schätzen als den Krieg.

Die Kultur der Genesiserzählungen ist überall die der Halbnomaden

I Vgl. den Text bei Gressunan, Texte und Bilder, Band I, S. 38 .

2 Vgl. die Ausführungen bei WUNDT, Völkerpsychologie II, 3. S. 350 f. 
oder Måāzc, wie ihr heutiger Spottname im Ostjordanland lautet ${ }^{x}$. Wo sich ihnen Gelegenheit zum Ackerbau bictet, benutzen sie sie, ohne deshalb zu Bauern zu werden. In Beerseba werden "Häuser" vorausgesetzt (27 15), dort hat man auch das Feld bestellt und unter anderem Linsen geerntet (25 34). Droht in Beerseba Mißwachs, so versucht man, in Gerar, dem philistäischen Negeb, sich schadlos zu halten ${ }^{2}$. So entspricht es den noch heute dort herrschenden wirtschaftsgeographischen Verhältnissen; denn Beerseba selbst ist fruchtbares Land, die Kornkammer Südpalästinas, während der Negeb im großen und ganzen ebenso wie die „Wüste" Juda nur zur Weide geeignet ist. Auf der anderen Seite sind die mehrfach im Besitz der Patriarchen erwähnten Kamele noch kein Beweis für Nomadentum. Auch Halbnomaden können Kamele haben, aber charakteristisch ist für sie das Züchten von Schafen und Ziegen, wie bei den Erzvätern tatsächlich der Fall ist. Die Nomaden können auf ihren raschen, bedürfnislosen Kamelen ein ungeheures Gebiet durchschweifen; Nordpalästina ist für die Zentralaraber nicht zu weit entfernt. Hingegen sind die Halbnomaden auf ein bedeutend kleineres Gebiet beschränkt; denn sie sind auf das Wasser angewiesen, .da ihre Herden täglich getränkt werden müssen. Der Streit um die Brunnen von Esek, Sitna, Rehoboth, Gerar, Beerseba füllt in der Tat das Leben der Patriarchen aus. Während die Nomaden fehdelustig sind, da sie nichts zu verlieren haben, schnell erscheinen und schnell wieder verschwinden können, sind die Halbnomaden friedliebend; denn eine Fehde könnte den ganzen Herdenbesitz gefährden. Demgemäß fehlt den Patriarchen die Tugend der Tapferkeit; sie suchen sich mit ihren Nachbarn so gütlich wie möglich, jedenfalls ohne Waffengewalt, zu einigen und schließen überall Verträge. Klugheit, oder noch richtiger, Verschlagenheit ist daher die Haupteigenschaft der

I Vgl. Alors MusiL, Arabia Peträa. Band III. S. 23.

2 GUNkEL hat sich in der dritten Auflage seines Kommentars (S. 220) entgègen seiner früheren Ansicht (2 S. 193) für die Identifizierung Gerars mit dem wādi ğerūr bei kudēs entschlossen, wie mir scheint, mit Unrecht. Er ist gezwungen, eine Verwechslung mit dem philistäischen umm ğarrār am eššserī̌a bei Gaza anzunehmen. Eine solche Verwechslung ist bei den israelitischen Sagenerzählern schwer begreiflich. Vielmehr weist die Nennung der Philister, das "Königtum" Abimelechs, auch wenn er kein Philister gewesen sein sollte, und die in Gerar vorausgesetzte Fruchtbarkeit des Bodens not. wendig nach dem wādi eš-šería, von dessen üppigen Gerstenfeldern noch heute die

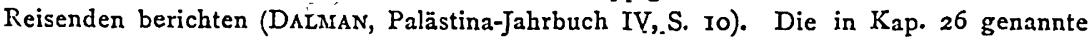
- Reihenfolge der Stationen (Gerar, Esek, Sitna, Rehoboth, Beerseba) kann man nicht dagegen anführen. Beerseba liegt allerdings nö. von Rehoboth, aber Sitna, wenn $=$ wādi šutẹn, $4 \mathrm{~km}$ n. von er-ruhẹebe (Gurhe, Kurzes Bibelwörterbuch s. v. Sitna)! Also ist Isaak von Gerar bis Rehoboth direkt südwärts gezogen und dann nach NO. umgebogen. 
Erzväter. Die Erzählungen, namentlich über Jakob, sind voll von den Schlichen und Schelmenstreichen, den Zauberpraktiken und Kunstkniffen der Hirten. Fügt man noch hinzu, was mit Geburt und Tod, Brautschau und Hochzeit zusammenhängt, so hat man die Motive dieser Kultursagen vollzählig gesammelt und damit zugleich einen kulturhistorisch äußerst lehrreichen Einblick in das Leben der Erzähler gewonnen.

Die Dreiteilung der Bewohner Palästinas geht am deutlichsten aus der Sage von Kain und Abel hervor (4i-16). Man versteht sie nur dann völlig, wenn man scharf unterscheidet zwischen den Halbnomaden (= Schafhirten), die an der Grenze des Kulturgebietes oder auf der Trift wohnen, den Ackerbauern, die im Fruchtlande seßhaft sind, und den Nomaden, die unstät in der Wüste umherschweifen. Der Erzähler selbst gehört, wie aus seiner Parteinahme zu schließen ist, zu den Halbnomaden '. Denn Abel, der als Schafhirt die Erstgeburt der Herde darbringt, wird von Gott bevorzugt. Der Ackerbauer Kain dagegen opfert Früchte, was Jahwe nicht liebt. Das Problem, das den Halbnomaden bewegt, ist die Frage, wie der Nomade zu seinem entsetzlichen Leben gelangt ist. Die Antwort lautet, weil er einen Brudermord begangen hat ${ }^{2}$ und seitdem vom Acker vertrieben ist. Der Halbnomade fühlt sich demnach im Gegensatz zu den Bauern auf der einen und den Nomaden auf der anderen Seite. Er gibt seiner Verachtung gegen beide Ausdruck, indem er den Bauern zum Brudermörder macht, der, wie es in Wirklichkeit oft genug vorkommen mochte, einen Schafhirten erschlagen hat, und indem er den Nomaden für einen verfluchten Bauern erklärt. Die Voraussetzung ist also für ihn, daß die Seßhaftigkeit älter ist als das Nomadentum ${ }^{3}$. Das

I GUNkEL3 S. 47 betont zwar richtig, daß die Kreise, die sich diese Sage zuerst erzählten, halbseßhafte 'Schafhirten waren, aber unrichtig fügt er hinzu, daß sie „also“" selbst „auf dem Fruchtboden" lebten.

= Die Vermutung, dał das Kainzeichen ursprünglich ein Jahwezeichen gewesen sei, scheint mir völlig unmöglich. Denn wenn es auch gegen die Blutrache schützen soll, so wird es doch einem Brudermörder verliehen! Wie konnten Verehrer Jahwes so etwas über den Ursprung des Jahwezeichens erzählen? Jahwe ist hier vielmehr wie in der Bileamgeschichte ganz allgemein $=$ Gott. Es muß spezielle Mörderzeichen im Unterschied von den Stammeszeichen gegeben haben. Vgl. eine Fülle von Material bei Frazer in dem o. S. 19 Anm. 2 genannten Buch S. $102 \mathrm{ff}$.

3 Mit Unrecht schließt ED. MEYER, Israeliten S. 395, in dem höheren Alter Kains komme zum Ausdruck, "daß die halbe Seßhaftigkeit des Viehzüchters und nun gar die volle des Bauern jünger ist als das Leben des Beduinen". Die Reihenfolge der Lebens. weisen ist im Gegenteil: 1. Ackerbau (der ursprüngliche Káin), 2. Halbnomadentum (Abel), 3. Vollnomadentum (der verfluchte Kain). Übrigens wird auch Adam nach der Vertreibung aus dem Paradies kein Nomade, sondern ein Ackerbauer. Da gilt der Ackerbau als Fluch! Stammt diese Anschauung wirklich aus den Kreisen der Bauern? 
Motiv des Brudermordes ergab sich darum von selbst, da ansässige Leute nur zu Nomaden werden, wenn sie die Blutrache zu fürchten haben. $\mathrm{Zu}$ gleich erkennt man, daß der Halbnomade dem Ackerbauer näher steht als dem Beduinen, dessen Los ihm schrecklich, unheimlich und des Nachdenkens wert erscheint.

Wie man in der vorliegenden Geschichte von dem Opfer der erstgebornen Herdentiere und dem ihres Fettes erfährt, so tritt in anderen Kultursagen als das charakteristische Merkmal der Hirtenstämme in religiöser Beziehung die Verehrung der Elim hervor. Man hat gar keinen Grund, diese Elreligion für die der „Eingebornen“ zu halten, von denen Israel die heiligen Stätten und die dazu gehörigen Lokalnumina entlehnt hätte ${ }^{x}$. Denn einerseits pflegten die Kanaaniter ihre Götternamen nicht mit El, sondern mit Baal zu bilden. Baal aber wird bezeichnender Weise in der ganzen Genesis nicht ein einziges Mal erwähnt. Trotzdem zwischen El und Baal kein sachlicher Unterschied vorhanden ist, darf man die Differenz der Namen nicht verwischen. Wir haben ein analoges Beispiel an Baalath. Obwohl Baalath das Femininum zu Baal ist und demgemä $\emptyset$ häufig vorkommen sollte, ist sie nur ein einziges Mal, als Gottheit von Gebal (Byblos), bezeugt. Die Kanaaniter waren eben gewohnt, ihre Göttinnen nicht Baalath, sondern Aschera zu nennen. Die Frage nach dem Warum ist nicht $z u$ beantworten. Andererseits sind gerade in der Genesis eine Fülle von Eigennamen vorhanden, die mit El zusammengesetzt sind, so die Hauptpersonen der Vätersage: Israel, Ismael und ursprünglich auch Isaakel, Jakobel, Josephel. Mit welchem Recht will man dies theophore Element als fremdländischer Herkunft ausgeben? Da nun Komposita mit Jahwe oder Baal völlig fehlen, so darf man die Frage aufwerfen, wie denn der Gott jener Halbnomaden anders gelautet haben soll als El? Im Gegenteil, man darf sagen, daß die ältesten Erzähler der Genesisgeschichten von Jahwe nichts wußten oder wissen wollten. Ihre Elreligion ist von der Jahwereligion des späteren Israel wohl zu unterscheiden.

So sind die Kultursagen ${ }^{2}$ profangeschichtlich wie religionsgeschichtlich von eminenter Bedeutung. Ihr Wert wird noch größer, wenn wir imstande sind, den Ort und die $Z$ eit ihrer Entstehung zu bestimmen. Stellt man alle in der Genesis genannten Orte, soweit sie hier in Betracht kommen, zusammen, so ergibt sich das überraschende Resultat, daß sie sich keineswegs über ganz Palästina erstrecken, wie man erwarten sollte,

I So GuNKEL 3 S. 187236285.

2 Als solche sind zu bezeichnen Kap. $42_{22^{-24}} 24_{22_{33}}^{29} 26_{3}$ I. 
sondern ausschließlich über drei Landschaften: die Gegend um Hebron und Beerseba, um Sichem und Bethel, um Penuel und Mahanaim. Wie Wellhausen behaupten kann", die Patriarchensage ,habe im mittleren und nördlichen Israel ihren eigentlichen Boden", ist mir unbegreiflich, da es sich deutlich um die Wüste Juda und den Negeb, d.h. Südpalästina, ferner um das Gebiet am Jabbok, d. h. Ostpalästina, und um einen kleinen Teil Mittelpalästinas handelt ${ }^{2}$.

So einfach der Tatbestand ist, so schwierig ist seine Erklärung. Woher just jene Auswahl eines verblüffend geringen Bezirkes im eigentlichen Palästina? Warum fehlen Sagen von den später so berühmten Stätten wie Jerusalem, Silo, Mispa, Rama, Gibeon, Gilgal, Dan, Samaria? 3 Eine sichere Antwort ist unmöglich, aber die nächstliegende Vermutung scheint mir zu sein, daß man es mit einer Sammlung südpalästinischer Sagen aus der Zeit vor Saul zu tun hat ${ }^{4}$. Die Hirtenstämme, die in der Wüste Juda und dem Negeb zelteten, deren Sagen vornehmlich um Abraham und Isaak gruppiert sind, darf man in der Hauptsache mit dem späteren" Juda identifizieren. Die Hypothese, dalb Juda von Süden her nach Palästina eingedrungen ist, hat man längst aufgestellt; sie würde, wenn diese Rekonstruktion der Sagengeschichte richtig ist, eine glänzende Bestätigung und Rechtfertigung erhalten. Bis auf die Zeit Sauls hat Juda seine eigene Geschichte erlebt; da erst reichte es dem nördlichen-Bruder Israel die Hand. Ehe die großen Städte, Bethlehem, Jerusalem, Hebron erobert wurden, kann Juda nicht gut anderswo gewohnt haben als in der Wüste und im Negeb. Seine von Israel abweichenden Schicksale lassen es begreiflich erscheinen, $\mathrm{da} B$ uns in der Genesis eine bis zu einem gewissen Grade andere Religion entgegentritt als in den übrigen Büchern des Alten Testaments. Hier soll nur an die Elreligion erinnert werdens. Nun sind aber in die Genesis Sagen aufgenommen, die in der Umgegend von Sichem. spielen. Da nach der Überlieferung (Kap. 34) Simeon und Levi dort geweilt haben, dann aber

× Prolegomena 4 S. 323.

2 Das Richtige bei ẼD. MEYER, Israeliten S. $472 \mathrm{fr}$.

3 Auf dies Problem hat EeRdunss II, S. 30 treffend hingewiesen.

4 Die Frage nach der Heimat des Jahwisten und Elohisten scheint unbeantwortbar. Da der Elohist die Kultussage von Bethel erzählt, so gibt man ihn für einen Ephraimiten aus (so ED. MEYER, Israeliten S. 27 I u. a.). Da ED. MEYer (ebenda S. 260) behauptet, der Elohist habe ein grobes Interesse an Beerseba, so darf man ihn mit demselben Recht für einen Judāer halten. Wenn man gar gesagt hat, Beerseba habe politisch zum Nordreich gehört, so ist das eine unerlaubte Harmonistik.

5 Vgl. weitere Beobachtungen bei GrzSSMANN, Ursprung der israelitisch-jüdischen Eschatologie S. 129 Anm. 1. 
durch die Kanaaniter von dort vertrieben und später ${ }^{x}$ vernichtet worden sind, so darf man wohl vermuten, daßj die mittelpalästinischen Sagen der Genesis von ihnen geschaffen und den Judäern übermittelt wurden. Simeon (Levi) und Juda gehören auch nach anderen Traditionen aufs engste zusammen: beide sollen gemeinsam und vor den übrigen israelitischen Stämmen in Palästina eingedrungen sein, und Simeon soll sich später in Zephath-Horma niedergelassen haben (Jdc I), also in der nächsten Nachbarschaft Judas. In der Zeit Davids haben Simeon und Levi, soviel darf man sicher sagen, nicht mehr existiert, wahrscheinlich ist aber ihre Vernichtung sehr viel älter ${ }^{2}$. So läßt sich die Vermischung jüdischer Sagen mit simeonitischen Bestandteilen vor der Zeit Sauls gut begreifen. Endlich sind noch die Sagen der Jabbokgegend hinzugekommen. Nun hat im Ostjordanland zweifellos der Stamm Ruben gesessen, wenn auch auf die genauere Tradition über seine Ortschaften kein Verlaß ist. Vergleicht man die Karte Palästinas und sieht man, wie der Jabbok ungefähr östlich von Sichem in den Jordan einmündet; dann mag wohl die Möglichkeit einleuchten, daß die Gebiete um Sichem und Penuel einst eine politische Einheit gebildet oder wenigstens die gleichen Schicksale erlebt haben. Die Vernichtung Rubens könnte zu gleicher Zeit erfolgt sein wie die Simeons und Levis. Leider fehlen alle Nachrichten, so da $\$$ man aufs Raten angewiesen ist. Postuliert man aber nur das Eine, daß Ruben am Jabbok wohnte3, dann ist die Aufnahme rubenitischer Sagen in ein judäisches Sagenbuch verständlich. Denn bei der unmittelbaren Nachbarschaft mußten die Simeoniten und die Rubeniten ihre Sagen miteinander austauschen. Wie eng Ruben, Simeon, Levi und Juda zusammen gehörten, erkennt man noch aus der Genealogie, die sie als die vier ältesten Söhne Jakobs zusammenfaßt. Durch die Sagengeschichte wird ihre Verwandtschaft bestätigt4.

I Darin wird Ed. Meyer, Israeliten S. 412 ff. Recht haben, daß Simeon und Levi nach dem Weggange von Sichem zunächst gerettet wurden $\left(35_{5}\right)$. Seinen übrigen Schlußfolgerungen vermag ich nur teilweise zuzustimmen. Die besondere Hervorhebung von Simeon und Levi unter den Söhnen Jakobs lehrt jedenfalls deutlich, daß es sich um ein Erlebnis dieser beiden Stämme, nicht Gesamtisraels, handelt.

2 Jdc I, das bis zu einem gewissen Grade gut unterrichtet ist, weif von der Vernichtung Simeons nichts mehr, kennt aber noch den Sitz seiner Reste, die es als Appendix Judas betrachtet.

3 Man könnte vermuten, da $\beta$ Gen $35_{2 x}$ f., wo. die Schandtat Rubens angedeutet wird, durch den Namen "Israel" als direkte Fortsetzung der Penuelgeschichte verstanden sein will. Dann würde Migdal Eder ebenfalls in der Nähe des Jabbok zu suchen sein, eben da wo Ruben zu Hause ist.

4 Die Josephsagen haben so wenig Lokalkolorit, daß man schwerlich ein Recht hat, 
Mit der Zeit Sauls ist der Endtermin gegeben, bis zu dem die Sagen der Genesis im großen und ganzen fertig waren, wenn auch Einzelheiten später hinzugefügt sind. Diese verschwindenden Beziehungen auf die israelitische Königszeit haben früher die Meinung nahegelegt, als seien die Patriarchenerzählungen erst in der Königszeit entstanden und spiegelten die damaligen Verhältnisse wieder. Davon kann schlechterdings keine Rede sein ${ }^{x}$. Die Königszeit darf nur als diejenige gelten, in der die Sagen ihre letzte, endgültige, uns heute überlieferte Gestalt erhielten. Auch die stammesgeschichtliche Umdeutung der Sagen ist damals längst vollzogen, und prophetischer Einfluß macht sich nirgendwo bemerkbar ${ }^{2}$. Dem Inhalt und auch der Form nach müssen die Patriarchenerzählungen in eine sehr viel ältere Zeit zurückreichen. Es fragt sich, ob wir noch den terminus a quo bestimmen können.

Wie alt ist die geschichtliche Erinnerung Israels überhaupt? Als zuverlässig können nach dem gegenwärtigen Stande der Forschung nur diejenigen Nachrichten angesehen werden, die durch Denkmäler anderer Völker bestätigt sind. Auf guter Überlieferung beruht zunächst die Tradition von der Stadt Assur, die auf dem westlichen Ufer des Tigris gelegen hat (Gen 2 14). Diese Einzelheit weist in die Zeit vor 1300 v. Chr., denn damals wurde Assur durch die Hauptstadt Kelah ersetzt. Auf eine noch ältere Zeit deutet Num I3 22, wonach die Stadt Hebron sieben Jahre vor Zoan in Ägypten gebaut sein soll. Eine Inschrift Ramses II. (I292-12.25 v. Chr.) ist datiert vom Jahre 400 nach Einführung des Sethkultes in Tanis ( - Zoan). Die Ära würde demnach um 1680 v. Chr. beginnen und die Gründung Hebrons etwa ins Jahr I687 v. Chr. fallen 3. Da Tanis eine Stadt der Hyksos war, so ist wahrscheinlich mit der biblischen Notiz auf das 17. Jahrhundert angespielt, mag auch jene Ära, wie RANkE behauptet4, nicht existiert haben. Besonders beachtenswert ist die Angabe wegen ihres rein geschichtlichen Charakters. Das älteste Gut' aber ist in dem historischen Rahmen der

sie für ephraimitischen Ursprungs zu halten. Wäre das der Fall, so würde man auch einen vie! stärkeren stammesgeschichtlichen Einschlag erwarten. Die wenigen Stammesnotizen konnte man auch in Juda wissen.

I Vgl. auch díc in dieser Beziehung vortreflichen Ausführungen von Eerdsans Alttest. Stud. II, S. $28 \mathrm{ff}$.

2 Vgl. die Ausführungen Gunkels² S. LXXIX, die ich ganz unterschreibe. Man darf sogar noch weitergehen-und auch die Abneigung gegen Jahwebilder und Ascheren bezweifeln. Woher weil' man denn, dab es solche überhaupt gegeben hat?

3 Vgl. ED. MEYER, Israeliten S. 447:

4 Die Religion in Geschichte und Gegenwart. Bd. I, Sp. 207. 
spätjüdischen Legende Gen 14 aufbewahrt: Danach hätte Kedorlaomer von Elam mit seinen Vasallen einen Zug nach dem Westen unternommen. Das ist durch dic Keilschriften zwar nicht direkt bestätigt, aber doch wahrscheinlich gemacht. Zunächst ist Kedorlaomer ein gut elamitischer Name (wie Kudur-mabuk, Kudur-nachundi). Ferner heibt Kudur-mabuk „adda von Amurru", Herrscher des Amoriterlandes; er mul also die Amoriter des Westens besiegt haben, und was von ihm gilt, darf auch von Kedorlaomer, einem seiner Nachfolger, vermutet werden. Als sein Vasall wird Arjoch von Larsa bezeichnet: in der Tat hat Kudur-mabuk um I970 v. Chr. die Dynastie von Larsa unterworfen; Waradsin, der Bruder Rimsins, kann eri-aku (= Arjoch) geheißen haben ${ }^{x}$. Als zweiter Vasall der Elamiter wird Amraphel = Hammurapi genannt. Nun führt das 30. Regierungsjahr Hammurapis den Namen "Jahr des Heeres von Elam", das 3r. "Jahr des Heeres von Emutbal". Beide Nachrichten könnte man so miteinander kombinieren: zuerst hat Hammurapi zusammen mit Waradsin, dem nach der Eroberung Larsas durch die Elamiter der kleine Pufferstaat Emutbal geblieben war, die Elamiter unterjocht, sich dann aber gegen seinen bisherigen Bundesgenossen gewandt. Hammurapi (1958-1916) wäre demnach 1958-1929 Vasall der Elamiter gewesen, und Gen I4 könnte etwa in die Zeit um I950 v. Chr. zurückreichen, soweit es geschichtliche Kunde enthält. Da aber die Erzählung im Übrigen durchaus den Stempel der Legende trägt und in der nachexilischen Zeit geformt $z u$ sein scheint, so ist wohl anzunehmen, daß der Stoff nicht aus israelitischer, sondern aus aramäischer Tradition stammt und einer aramäischen Weltchronik entlehnt ist ${ }^{2}$. Gute Erinnerung hat die israelitische Überlieferung auch an die Existenz der Hettiter in Palästina übermittelt (Gen 232634 f. 27 46), obwohl sich diese Notizen bisher leider nicht datieren lassen. Der König Abdichipa der Amarnabriefe heißt nach einer hettitischen Göttin. Wenn es damals Hettiter in Jerusalem gab, dürfen sie auch in Hebron und anderswo vorausgesetzt werden. Nach alledem sind mancherlei Nachrichten der Genesis aus dem zweiten Jahrtausend, die man früher angefochten hat, durch die Kontrolle der Keilschriften und Hieroglyphen zuverlässig erhärtet. Bei dem sagenhaften Charakter darf man sich über die Dürftigkeit des Materials nicht wundern, im Gegenteil, eher darf man staunen, daß überhaupt eine solche Bestätigung in Einzelheiten Tatsache ist, und man darf mit Gewißheit hoffen, $\mathrm{da} ß$ manche andere Tradition durch neue Funde erhellt wird. Die $\mathrm{Zu}$ -

I Mündliche Mitteilung des Herrn Professor Ungnad.

2 Vgl. Ed. MeYer, Geschichte des Altertums2. Bd. I, 2. S. $55 \mathrm{If}$. 
versicht $z \mathbf{u}$ der Überlieferung ist jedenfalls im Steigen begriffen, wenn auch noch viele Rätsel ungelöst bleiben.

ED. MEYER hat I als drastischen Beleg für die relative Jugend der alttestamentlichen Überlieferung angeführt, daß sie nicht die mindeste Kenntnis von der jahrhundertelangen Herrschaft der Ägypter über Palästina verrate. Aber er hat selbst eine Fülle von Tatsachen aufgezählt, die einen engen Zusammenhang Palästinas mit Ägypten beweisen: die Gestalt Nimrods(?), den Ritus der Beschneidung, die Namen Mose und Pinehas, das Schema der prophetischen Orakel. Vor allem aber ist $z \mathrm{u}$ betonen, wie ausgezeichnet gerade die Genesis über Ägypten und ägyptische Verhältnisse Bescheid wei@. $\mathrm{Zu}$ den Abenteuer- und Kultursagen, die mit Joseph verbunden sind, gesellt sich noch die Erzählung von dem Aufenthalt Saras im Harem des Pharao. Wie naturgetreu hier der Pharao geschildert wird, geht aus der Zauberformel in der Pyramide des Unas hervor, die dem toten Herrscher den Gebrauch seiner Gliedmaßen wieder verschafft: „Da nimmt er die Weiber ihren Gatten weg, wohin er will, wenn sein Herz die Lust ergreift" . Der lebende König war gewi $@$ nicht besser als der tote 3 . Ferner aber ist merkwürdig, da $\$$ Kanaan nach der biblischen. Genealogie ein Sohn Hams ${ }^{4}$ und ein Bruder Misraims ist (Gen 9 18 106). Das erklärt sich weder aus der Sprache Kanaans, noch aus seiner geographischen Lage, sondern nur aus den kulturhistorischen Verhältnissen: Kanaan erschien den Israeliten wie eine ägyptische Provinz. Deutlicher als hier kann es doch kaum zum Ausdruck kommen, wie sehr Palästina unter dem Einfluß Ägyptens gestanden hat. Ferner ist zu bedenken, daß die hebräischen Stämme zu einer Zeit einwanderten, wo die ägyptische Herrschaft bereits im Rückgang begriffen war und zum Teil nur noch nominell aufrecht erhalten wurde. Endlich darf man die Frage aufwerfen, welche Nachricht man denn eigentlich erwartet, etwa die, daß Abraham oder Isaak oder Jakob Vasallen

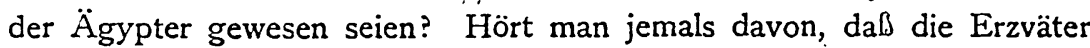

I ED. NEYER, Isracliten S. $446 \mathrm{ff}$.

2 ED. MEYer, Geschichte des. Altertums² I, 2. S. 142.

3 Wen dieselbe Geschichte auf Abimelech von Gerar übertragen ist, so ist das eine sekundāre Neuerung (gegen Gunkel). Denn quod licet Jovi non licet bovi! Wenn weder der Pharao noch seine Residenz mit Namen genannt werden, so ist das auch kein Zeichen „,blasser Vorstellungen von Ägypten", sondern gehört zum Wesen solcher Aben. teuersagen.

4 Gen ${ }_{27}$ ist wohl statt des völlig sinnlosen: באהלי שם zu lesen: Ham und Kanaan sind hier Synonyma. Dann versteht man nicht nur diesen Spruch besser, sondern auch die Glosse in 918 ,Ham ist der Vater Kanaans" und 922 , wo dieselbe Tat dem Ham zugeschrieben wird, die nach dem Folgenden Kanaan begangen hat.

Zeitschrift f. d. alttest. Wiss. Jahrg. 30. 1910. 
Untertanen der Fettiter oder Kanaaniter waren? Sie begegnen uns überall als die völlig selbständigen Herren in ihrem Bereich, die zwar bisweilen mit den Philistern, Hettitern und Kanaanitern in Berührung kommen, im großen und ganzen aber friedlich und ungestört leben.

Allein ist nicht gerade dies ein Kennzeichen für die Unzuverlässigkeit der israelitischen Überlieferung, daß sie kein lebensvolleres Bild von den Zuständen in Palästina entwirft? Es bedarf nach dem Vorangegangenen kaum noch der Ausführung, daß diese Fragestellung falsch ist. Da die Sagen nicht „aus Palästina" stammen, sondern nur aus bestimmten Teilen des Landes, so darf man jenen Anspruch gar nicht erheben. Tritt man hingegen nicht mit falschen Erwartungen an die Genesis heran, so wird man auch - nicht enttäuscht. Oder kann es ein anschaulicheres Gemälde geben als das vom Leben der Hirtenstämme in der Wüste Juda und im Negeb, das uns in den Erzählungen über Abraham und Isaak vorliegt? Wer dort wohnt, ist politisch immer frei gewesen. Die Macht der ägyptischen Regierung hat höchstens vorübergehend dorthin gereicht, wie die Sauls oder die der türkischen Regierung. Im übrigen lernen wir die Nachbarn, mit denen sich die Hirten friedlichschiedlich auseinandersetzen, alle kennen: die Hettiter in Hebron, die Philister in Gerar, die Ismaeliter in Beer lachai roi, die Kainiter, Edomiter, Moabiter und Ammoniter. Wenn der Historiker trotzdem nicht zufrieden ist, so soll er die Schuld nicht auf die Überlieferung, sondern auf die Gegend schieben; in der Wüste gibt es keine Geschichte. Ebenso wertvolle, kulturhistorische Schilderungen enthalten die Erzählungen, die am Jabbok lokalisiert sind und Berührungen "Jakobs" mit den Aramäern verzeichnen, während Levi und Simeon in Sichem mit den Kanaanitern in Konflikt geraten. Von ihrem Geschick und dem Untergang Rubens würden wir mehr erfahren, wenn nicht eine Bearbeitung des Textes stattgefunden hätte, die die vorhandenen Berichte bis auf wenige Zeilen verstümmelt hat. In diesem Falle sind also spätere Zensoren, aber nicht die ursprünglichen Erzähler verantwortlich zu machen. Das Wenige, was an Daten geblieben ist, gestattet keine sichere Zeitangabe für die vorausgesetzten Ereignisse. Wenn man alle Umstände, die hierfür in Betracht kommen, sorgfältig erwägt, so wird man wohl ungefähr die Periode von I300-I 100 v. Chr. als die Entstehungszeit für die große Masse-der Einzelerzählungen in der Genesis betrachten dürfen. 